\title{
Dormant Cathode Plasma Properties and Erosion Analysis in a Multiple-Cathode, High-Power, Rectangular Discharge Chamber
}

\author{
Joshua L. Rovey ${ }^{*}$ and Alec D. Gallimore ${ }^{\dagger}$ \\ Plasmadynamics and Electric Propulsion Laboratory \\ Department of Aerospace Engineering \\ University of Michigan \\ 1919 Green Rd. Rm. B107 \\ Ann Arbor, MI 48109 USA \\ Phone: 734-764-4199 \\ Fax: 734-763-7158
}

\begin{abstract}
A high-power, rectangular discharge chamber is being investigated by the University of Michigan for operation with multiple discharge cathode assemblies (DCAs). The multiple cathode approach attempts to increase thruster lifetime by operating three DCAs sequentially, possibly providing a threefold increase in discharge life. Previous multiplecathode electric propulsion devices, such as the SPT-100, have shown dormant cathode erosion to be a life-limiting phenomenon. Similar results in a multiple-cathode discharge chamber (MCDC) may decrease the anticipated discharge lifetime. For the experiments presented here a MCDC test article (TA) is operated in the University of Michigan Large Vacuum Test Facility. In order to assess potential dormant cathode erosion, diagnostic cylinders (DCs) are designed and utilized to measure plasma properties at the dormant cathode locations. Each DC appears similar to the active DCA, but is outfitted with plasma diagnostics, such as Langmuir probes and a retarding potential analyzer (RPA). Langmuir probe results indicate that typical dormant cathode number densities, electron temperatures, and plasma potentials are $5.0 \times 10^{11} \mathrm{~cm}^{-3}, 5 \mathrm{eV}$, and $27 \mathrm{~V}$, respectively. Most probable ion energy measurement results are consistent with the plasma potential measurements. Pre-operation erosion rates for molybdenum (Mo) and graphite dormant cathode keepers are estimated based on sputter threshold, yield, ion incidence angle, and ion flux equations. Results suggest little to no graphite erosion and a Mo erosion rate between 0$40 \mu \mathbf{m} / \mathbf{k h r}$.
\end{abstract}

$\mathrm{A}_{\mathrm{c}} \quad$ Collection area $\left(\mathrm{m}^{2}\right)$

$A_{p} \quad$ Langmuir probe area $\left(\mathrm{m}^{2}\right)$

$\mathrm{B}_{\mathrm{i}} \quad$ Numerical coefficients

E Bombarding ion energy (eV)

$\mathrm{E}_{\mathrm{s}} \quad$ Heat of sublimation (eV)

$\mathrm{E}_{\text {th }} \quad$ Sputtering threshold energy $(\mathrm{eV})$

e Elementary charge $\left(1.6 \times 10^{-19} \mathrm{C}\right)$

$\mathrm{f}(\mathrm{V})$ Ion voltage distribution function

I Probe current (A)

$\mathrm{I}_{\mathrm{d}} \quad$ Discharge current (A)

$\mathrm{I}_{\text {emag }} \quad$ Electromagnet current (A)

$\mathrm{I}_{\mathrm{si}} \quad$ Ion saturation current (A)

$\mathrm{I}_{\mathrm{i}} \quad$ Ion current (A)

K Constant

\section{Nomenclature}

$\mathrm{M}_{\mathrm{i}} \quad$ Xenon ion mass $\left(2.18 \times 10^{-25} \mathrm{~kg}\right)$

$\mathrm{m}_{1} \quad$ Incident material atomic mass ( $\mathrm{kg} /$ atom)

$\mathrm{m}_{2} \quad$ Target material atomic mass ( $\mathrm{kg} /$ atom)

$\mathrm{n}_{\mathrm{e}} \quad$ Electron number density $\left(\mathrm{cm}^{-3}\right)$

$\mathrm{n}_{\mathrm{i}} \quad$ Ion number density $\left(\mathrm{cm}^{-3}\right)$

$\mathrm{r} \quad$ Langmuir probe radius $(\mathrm{mm})$

$\mathrm{S} \quad$ Erosion rate $(\mu \mathrm{m} / \mathrm{khr})$

$\mathrm{T}_{\mathrm{e}} \quad$ Electron temperature $(\mathrm{eV})$

$\mathrm{V} \quad$ Probe voltage $(\mathrm{V})$

$\mathrm{V}_{\mathrm{d}} \quad$ Discharge Voltage (V)

$\mathrm{V}_{\mathrm{k}} \quad$ Keeper potential $(\sim 4 \mathrm{~V})$

$\mathrm{V}_{\mathrm{p}} \quad$ Plasma potential $(\mathrm{V})$

$\mathrm{Y} \quad$ Sputter yield (atoms/ion)

$\mathrm{Z}_{\mathrm{i}} \quad$ Ion charge-state

\footnotetext{
* Graduate Student, Aerospace Engineering, AIAA Student Member

${ }^{\dagger}$ Professor, Aerospace Engineering, AIAA Associate Fellow

Copyright 2005 by Joshua L. Rovey

Published by the American Institute of Aeronautics and Astronautics, Inc. with permission.
} 


$$
\begin{array}{ll}
\Gamma_{i} & \text { Ion flux (ions } \left./ \mathrm{m}^{2}-\mathrm{s}\right) \\
\lambda_{D} & \text { Debye length }(\mathrm{cm}) \\
\rho_{2} & \text { Target material density }\left(\mathrm{kg} / \mathrm{m}^{3}\right)
\end{array}
$$

$\theta \quad$ Ion incidence angle (degrees) $\xi \quad$ Non-dimensional current correction

$\begin{array}{ll}\text { 5PLP } & 5 \text { planar Langmuir probe } \\ \text { 7PLP } & 7 \text { planar Langmuir probe } \\ \text { ACLP } & \text { Axial cylindrical Langmuir probe } \\ \text { APLP } & \text { Axial planar Langmuir probe } \\ \text { CLP } & \text { Cylindrical Langmuir probe } \\ \text { DC } & \text { Diagnostic canister } \\ \text { DCA } & \text { Discharge cathode assembly } \\ \text { GRC } & \text { Glenn Research Center } \\ \text { HARP } & \text { High-speed axial reciprocating probe } \\ \text { HiPEP } & \text { High power electric propulsion } \\ \text { JPL } & \text { Jet Propulsion Laboratory } \\ \text { LVTF } & \text { Large vacuum test facility }\end{array}$

5PLP 5 planar Langmuir probe

7 planar Langmuir probe

APLP Axial planar Langmuir probe

Cylindrical Langmuir probe

DCA Discharge cathode assembly

GRC Glenn Research Center

HARP High-speed axial reciprocating probe

JPL

Jet Propulsion Laboratory
Large vacuum test facility

\section{Introduction}

$\mathrm{N}$ ASA's Project Prometheus is advancing the future of space exploration by developing nuclear electric propulsion (NEP) technology for deep space missions. Ion thrusters are high-efficiency, high-specific impulse propulsion systems that are being proposed as the primary propulsion source for such missions. An ion thruster that can satisfy mission requirements will require long life, high-power, and high-specific impulse. NASA Glenn Research Center (GRC) has developed such an ion thruster through the High Power Electric Propulsion (HiPEP) project, ${ }^{1-3}$ and is currently focused on designing the Herakles ion thruster with the NASA Jet Propulsion Laboratory (JPL). Because an ion thruster must operate continuously for perhaps as long as 7-14 years for Prometheus-class missions ${ }^{4-6}$ assessing and increasing thruster lifetime is of foremost importance. Contemporary ion thrusters like the NASA Solar Electric Propulsion Technology and Applications Readiness (NSTAR) ion thruster are limited to $\sim 30,000$ hours $(\sim 3 \text { years })^{7,8}$ of operation and recent results suggest the NASA Evolutionary Xenon Thruster (NEXT) may have a comparable lifetime. ${ }^{9,10}$.

In order to increase thruster lifetime for Prometheus-class missions, the University of Michigan Plasmadynamics and Electric Propulsion Laboratory (PEPL) is investigating an ion thruster that utilizes three sequentially operated discharge cathodes. With this approach, a new discharge cathode is ignited when the previous one fails. Ideally, this approach will increase thruster discharge lifetime threefold, making longer mission times feasible.

The state-of-the-art in multiple cathode electric propulsion devices consists of two previous research endeavors: a double cathode ion thruster developed by Hughes Research Laboratories, ${ }^{11}$ and the Stationary Plasma Thruster, SPT-100. ${ }^{12}$ In order to reduce the bombardment of high-energy ions on a single cathode operated at large discharge currents, the Hughes Research Laboratories developed a discharge chamber containing two hollow cathodes. Operation of the discharge chamber was accomplished with both cathodes operating together at multiple discharge conditions, including low-discharge-current idling and operation with and without beam extraction. However, the cathodes were placed inside a plenum to facilitate uniform electron distribution, which caused significant increases in ion production cost. In fact, the plenum walls collected more ion current than was extracted in the ion beam. ${ }^{11}$

Results from a 5700 hour life test of the SPT-100 at JPL showed that an operating cathode can cause significant erosion of the non-operating cathode, thus reducing overall lifetime. ${ }^{13-15}$ Specifically, propellant leaking through the inactive cathode created a "glow" discharge that produced enough ions to cause significant erosion of the dormant cathode. The unused cathode actually eroded at the higher rate. Eliminating the "glow" discharge may reduce the dormant cathode erosion, but results still indicate the inactive cathode collects an order of magnitude higher current density than the active cathode. ${ }^{15}$

Because of the results obtained during the SPT-100 life test, the potential erosion of a dormant cathode inside a multiple-cathode discharge chamber (MCDC) must be investigated. If the dormant cathodes inside an MCDC have reduced lifetimes due to pre-operation erosion, ion thruster lifetime may not increase as much as expected. In order for discharge lifetime to increase by a factor of three for a triple-cathode MCDC, dormant cathode pre-operation erosion must be eliminated or fundamentally absent. With this in mind, PEPL is studying the near dormant cathode plasma properties in an MCDC to determine if the lifetime of these cathodes is affected. PEPL has designed 
diagnostic canisters (DCs) similar to the active discharge cathode assembly (DCA), but outfitted with plasma diagnostics, such as Langmuir probes and a retarding potential analyzer. Each DC is operated inside a MCDC to determine plasma properties at the dormant DCA locations. The following sections describe the experimental apparatus, data analysis procedure, results, erosion analysis, and conclusions for this series of experiments.

\section{Experimental Apparatus and Setup}

\section{A. Vacuum Facility}

The University of Michigan Large Vacuum Test Facility (LVTF) is used for all experiments presented. The LVTF is a stainless-steel vacuum chamber with a diameter of $6 \mathrm{~m}$ and a length of $9 \mathrm{~m}$. In order to reach high vacuum, the facility employs seven CVI TM-1200 re-entrant cryopumps, each of which is surrounded by an $\mathrm{LN}_{2}$ baffle. The cryopump system can be operated with any number of pumps in use. For the experiments described here only two cryopumps are operated, which yields a base pressure of $5.2 \times 10^{-7}$ Torr. The chamber pressure is monitored using two hot-cathode ionization gauges, an external and a nude gauge. Pressure measurements from the gauges are corrected for xenon using the known base pressure on air and a correction factor of 2.87 for xenon as described in Ref. 16. Corrected pressure for the nude ion gauge is reported as the background pressure in the chamber. A recent investigation of the pressure inside the LVTF during Hall thruster cold-flow operation has shown that the nude gauge provides better agreement with the true pressure of the facility ${ }^{17}$ Corrected operating pressures for all experiments reported here are below $4.2 \times 10^{-6}$ Torr on xenon. For more facility information see Ref. 17.

\section{B. MCDC Test Article (TA)}

The MCDC test article (TA) is assembled as described in Ref. 18. An electromagnet and a NEXT DCA are mounted to the backplate of the MCDC. An ion collection grid is mounted at the ion extraction plane because the MCDC is operated as a simulated ion thruster without beam extraction. ${ }^{19}$ Attachment of the ion collection grid, the electromagnet, and the NEXT DCA to the MCDC is referred to as the MCDC test article (TA) or simply, TA. In addition to this setup, DCs are attached at the two dormant cathode locations. A schematic of the TA along with the chosen coordinate system is shown in Figure 1.

The general electrical setup of the TA is nearly identical to that described by Brophy,${ }^{19}$ however, in this case an ion collection grid is utilized as the ion collection surface instead of high-voltage ion optics. The TA is operated with a 30 A discharge current, cathode common biased $+25 \mathrm{~V}$ with respect to ground, and a collection grid bias of $20 \mathrm{~V}$ below cathode common.

For the experiments presented here various electromagnet, DCA, and DC connectivity configurations are investigated. Most notably the DCA is operated at the left, center, and right locations for electromagnet currents of $0 \mathrm{~A},+5 \mathrm{~A}$, and $+10 \mathrm{~A}$. Furthermore, each of the DCs is operated both electrically connected and electrically isolated (disconnected) from the TA. During electrically connected operation the DC "cathode" is connected to cathode common and the "keeper" is connected to the anode through a $10 \mathrm{kOhm}$ resistor. A summary of the TA operational configurations is shown in Appendix A. Further information regarding TA operation is described in Ref. 18.

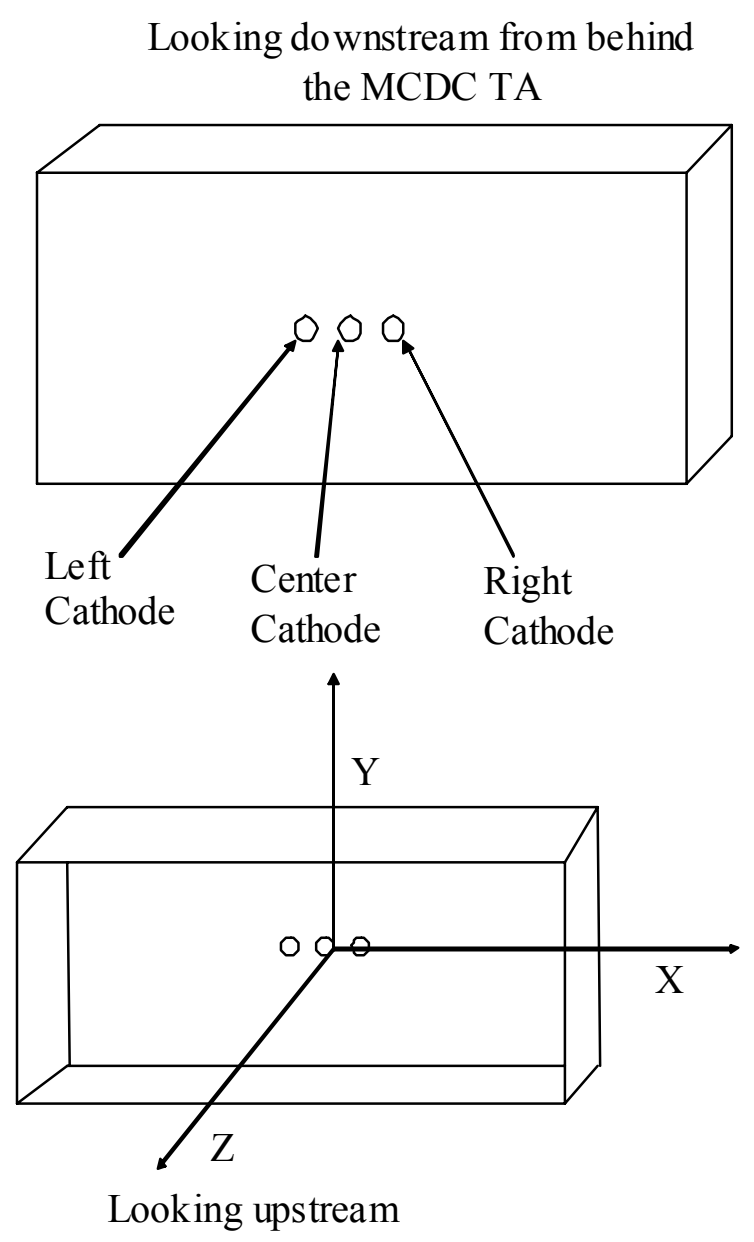

Figure 1: Coordinate system for the TA. 
Reference 18 describes TA operation for left and center DCA operation, but not for right DCA operation. Data presented here represents the initial operation of the TA with a right DCA. Assuming symmetry of the TA, operational flowrates for the right DCA are assumed equivalent to those obtained for left DCA operation. During right DCA operation TA performance is monitored and determined to be within $10 \%$ of the left DCA performance. Discharge voltage for right DCA operation is noticed to be $\sim 1 \mathrm{~V}$ higher. An explanation is not attempted.

\section{Diagnostic Canisters (DCs)}

Dormant cathode plasma properties are analyzed by designing and implementing DCs that appear similar in size and shape to the active DCA. This ensures that the TA plasma interacts with the DCs similarly to a dormant DCA. Five different DCs are presented in this paper; a 5 planar Langmuir probe DC (5PLP-DC); a 7 planar Langmuir probe DC (7PLP-DC); an axial planar Langmuir probe DC (APLP-DC); an axial cylindrical Langmuir probe DC (ACLP-DC); and a retarding potential analyzer DC (RPA-DC). The following sections describe the design, fabrication, and operation of each of the DCs.

\section{5 Planar Langmuir Probe (5PLP - DC)}

Two 5PLP-DCs are fabricated to make plasma property measurements at the two dormant cathode locations internal to the TA. Each DC appears similar to the active NEXT-DCA, however, each DC "keeper" is outfitted with 5 planar Langmuir probes at different spatial locations as shown in Figure 2. A cylindrical copper "keeper" is attached to a Macor insulator to form the base of the DC. The 5PLP-DCs do not contain a "cathode" electrode. Ten planar Langmuir probes (PLPs) are constructed of $0.16 \mathrm{~cm}$ (0.063") diameter tungsten wire surrounded by a 0.32 cm (0.13") outer diameter alumina tube yielding a probe area of $2.01 \mathrm{~mm}^{2}$. Each PLP is inserted axially into the DC such that the probe collecting surface is flush with the "keeper" faceplate. 5 PLPs are placed into each of the two DCs in a symmetrical pattern with each probe spaced $0.64 \mathrm{~cm}(0.25$ ") from the centerline axis. Ceramic epoxy is utilized to construct the probes, as well as to mate the probes, "keeper", and Macor insulator. Finally an aluminum mounting flange is utilized to attach the DC to the TA at one of the dormant cathode locations. This device is called a 5PLP-DC.

Each probe is connected to the biasing power supply through a $100 \mathrm{Ohm}$ shunt resistor as shown in Figure 2. Each probe bias voltage is set with the bias supply and the corresponding voltage drop across the shunt resistor is measured. Collected current is calculated by dividing the measured voltage drop by the shunt resistance. In this way the I-V characteristic for each probe is determined. Only one of the 5PLP-DCs is utilized during left DCA and center DCA operation because the RPA-DC is placed at the other dormant cathode location. Both 5PLP-DCs are

\section{Tungsten wire flush with Keeper}

a)

"Keeper" (Copper)

b)
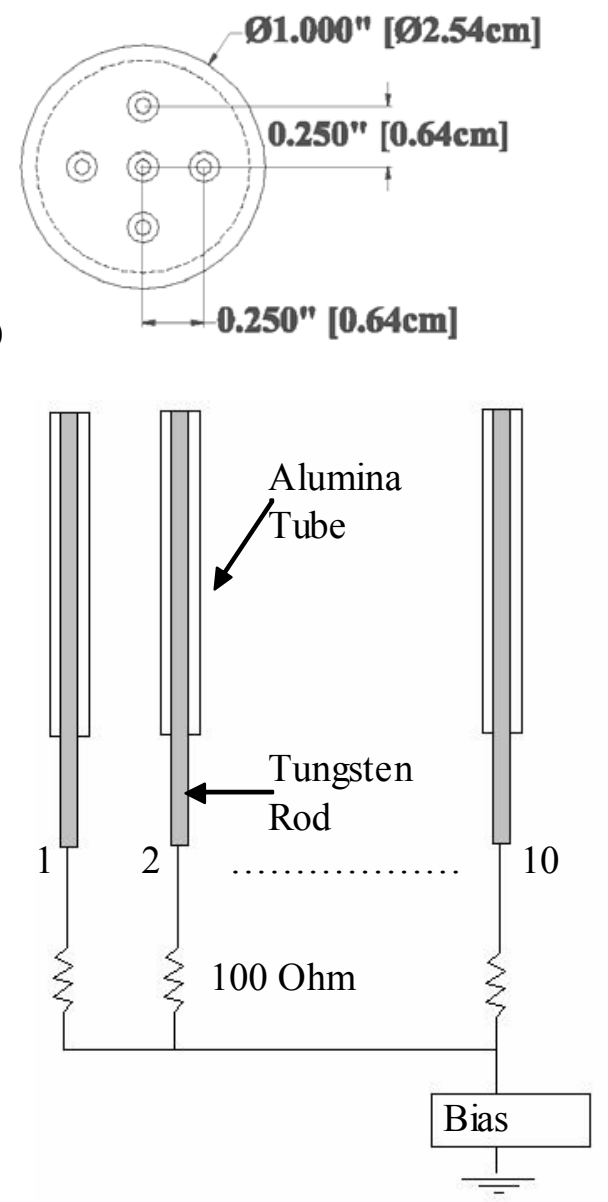

Figure 2: a) Schematic of the 5PLP-DC. b) Probe locations on the 5PLP-DC "keeper" faceplate. c) Electrical schematic of the planar Langmuir probes.

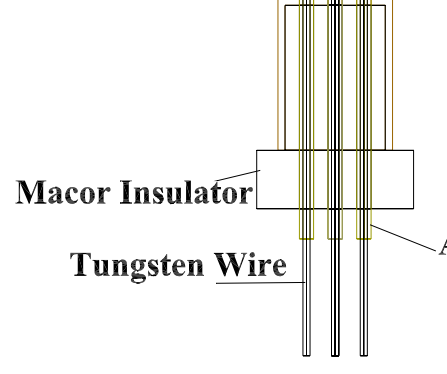


utilized during right DCA operation. Data are acquired with electromagnet currents of $0 \mathrm{~A}, 5 \mathrm{~A}$, and $10 \mathrm{~A}$, as well as with the DC electrically connected and electrically isolated from the TA. During electrically connected operation the "keeper" is connected to the anode through a $10 \mathrm{kOhm}$ resistor. As mentioned above, the 5PLPDC does not have a "cathode" electrode.

\section{7 Planar Langmuir Probe ( $7 P L P-D C)$}

Two 7PLP-DCs are also fabricated to make plasma property measurements at the two dormant cathode locations. The 7PLP-DCs are constructed identical to the 5PLP-DCs, except 7 probes are utilized instead of 5. A photograph of a 7PLP-DC is shown in Figure 3. Fourteen PLPs are constructed of $0.080 \mathrm{~cm}(0.031$ ") diameter

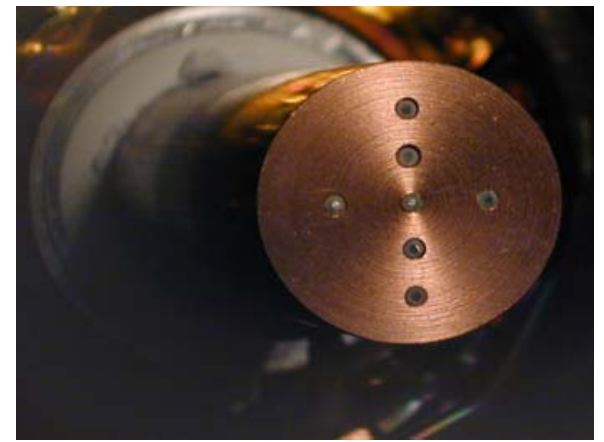

Figure 3: Photograph of the 7PLP-DC tungsten wire surrounded by a $0.16 \mathrm{~cm}(0.063$ ") outer diameter alumina tube yielding a probe area of $0.503 \mathrm{~mm}^{2}$. Electrically each of the probes is connected the same as the probes in the 5PLP-DCs shown in Figure 2, except a total of 14 probes and shunt resistors are utilized. 7PLP-DC I-V characteristics are obtained by the same procedure described for the 5PLP-DCs. Both of the 7PLP-DCs are utilized during left, center, and right DCA operation. Data are acquired for the same operational configurations as the 5PLPDCs. Because the probes are not symmetric about the DC centerline axis, during experimental testing one of the 7PLP-DCs is oriented with the TA y-axis and the other is oriented with the TA x-axis.

\section{Axial Planar Langmuir Probe (APLP - DC)}

The axial planar Langmuir probe (APLP) DC appears similar in size and shape to the active NEXT-DCA. Concentric "cathode" and "keeper" tubes are constructed of copper and held in place by a Macor insulator. "Keeper" and "cathode" orifice diameters are chosen to be identical to the active NEXT-DCA. A Macor insulator is utilized to hold the "keeper" and "cathode" at the required spacing. Two PLPs are constructed of $0.25 \mathrm{~mm}(0.010$ ") diameter tungsten wire housed in a $1.24 \mathrm{~mm}\left(0.049\right.$ ") outer diameter alumina tube yielding a probe area of $0.049 \mathrm{~mm}^{2}$. Each PLP is $17.8 \mathrm{~cm}$ (7.0") long and is inserted through the DC "cathode" tube to extend along the positive z-axis of the TA. The probe is concentric with the "cathode" and "keeper" tubes and is moved axially with respect to the "cathode" orifice. A $5.1 \mathrm{~cm}$ (2.0") alumina guide tube is inserted in the "cathode" tube to assist the PLP in passing through the "cathode" and "keeper" orifices. This setup allows the planar probe to be positioned over a $12.7 \mathrm{~cm}$ (5.0") range (10.2 cm (4.0") external and $2.5 \mathrm{~cm}(1.0 ")$ internal to the "cathode"). This setup is referred to as the APLP-DC. A schematic of the APLP-DC is shown in Figure 4.

Langmuir probe I-V characteristics are obtained at various axial locations to determine axial plasma properties at the dormant cathode locations. APLP-DC data are obtained for both left and center DCA operation with the electromagnet at $0 \mathrm{~A}, 5 \mathrm{~A}$, and $10 \mathrm{~A}$. APLP-DC data are not obtained for right DCA operation due to time constraints. The APLP-DC is operated both electrically connected and electrically isolated from the TA. During electrically connected operation, the APLP-DC "cathode" is connected to cathode common and the "keeper" is connected to the anode through a $10 \mathrm{kOhm}$ resistor.

\section{Axial Cylindrical Langmuir Probe (ACLP - DC)}

Axial cylindrical Langmuir probe (ACLP) DC construction and appearance is nearly identical to the APLPDC. In this case, however, a cylindrical Langmuir probe (CLP) is utilized. Two CLPs are constructed of $0.25 \mathrm{~mm}$ (0.010") diameter tungsten wire housed in a $1.24 \mathrm{~mm}$ (0.049") outer diameter alumina tube with the tungsten extending $3.2 \mathrm{~mm}(0.13$ ") beyond the tube. This yields a probe area of $2.56 \mathrm{~mm}^{2}$. Each of the CLPs is $15.2 \mathrm{~cm} \mathrm{(6.0")}$ long and the probe is positioned over a $10.2 \mathrm{~cm}(4.0$ ") range (7.6 cm (3.0") external and $2.5 \mathrm{~cm}(1.0 ")$ internal to the "cathode"). ACLP-DC data are obtained for the same operational configurations as the APLP-DC. However, right DC axial profiles are not obtained due to time constraints.

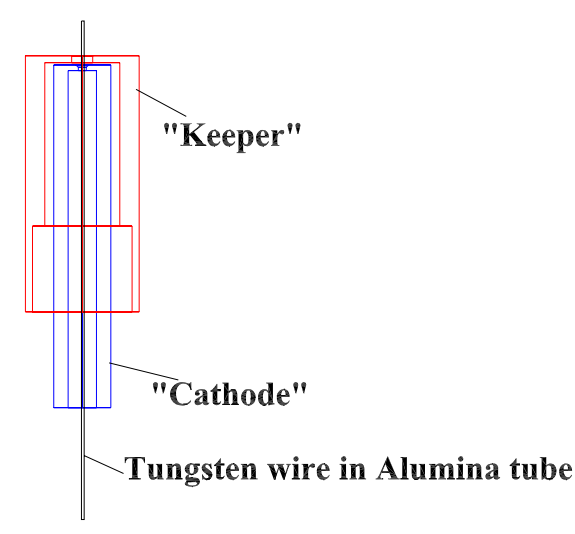

Figure 4: Schematic of the APLP-DC 


\section{Retarding Potential Analyzer (RPA-DC)}

The retarding potential analyzer (RPA) DC appears similar in size and shape to the active NEXT-DCA. However, the "cathode" tube has an internal, miniature RPA. The miniature RPA is designed based on the multi-gridded energy analyzer described in Ref. 20, the RPA described by Hofer, ${ }^{21}$ and the RPA utilized by Azziz. ${ }^{22}$ Outer dimensions of the miniature RPA are approximately the same as the RPA described by Azziz, ${ }^{22}$ which is approximately $50 \%$ smaller than that described by Hofer. ${ }^{21}$ The miniature RPA outer body is constructed of stainless steel with a diameter of $1.3 \mathrm{~cm}(0.50$ ") and has an entrance aperture identical to the active DCA orifice. Internal to the RPA are three grids, four ceramic spacers, and a collector. Each grid is stainless steel with a 0.13 $\mathrm{mm}(0.005$ ") thickness and $0.28 \mathrm{~mm}(0.011$ ") diameter holes arranged in a staggered pattern with a center-to-center spacing of $0.43 \mathrm{~mm}(0.017$ ') to yield an open area fraction of $38 \%$. The first grid is allowed to float in order to reduce the number density internal to the RPA. The second grid is biased $25 \mathrm{~V}$ below cathode common in order to repel electrons from reaching the collector. The potential of the third grid is swept from $-25 \mathrm{~V}$ to $45 \mathrm{~V}$ with respect to cathode common to repel ions. Finally, the collector is connected to ground through a picoammeter to measure the collected current. Ceramic boron nitride spacers are used to isolate the grids and collector electrically. The electrical connectivity for each grid and the thickness of the spacers is described in Figure 5 and Table 1

The miniature RPA is placed inside a stainless steel "keeper" tube and electrically isolated by another ceramic spacer. In this way, the body of the miniature RPA functions as the dormant "cathode" with the grids located internal to the "cathode". This setup is called the RPA-DC. A photograph and schematic of the RPA-DC are shown in Figure 5. Not shown in the photograph or the schematic are the two grids placed external to the RPA-DC covering the "keeper" orifice. These grids are required to reduce the plasma number density internal to the RPA. In order to function properly the gap distance between grids 2 and 3 must be less than approximately 4 times the Debye length $\left(\lambda_{\mathrm{D}}\right)$ to avoid space charge limitation of the grids. ${ }^{20}$ Initially, operation of the RPA is unsuccessful due to a large number density and hence a small Debye length. Adding grids external to the "keeper" is required to lower the number density such that the Debye length meets the criteria described above. The external grids act only to reduce the open area fraction of the "keeper" orifice and reduce the quantity of plasma present. Therefore the energy distribution of ions entering the RPA through the grid-covered "keeper" orifice is assumed to be unaffected by the external grids.

The RPA-DC is utilized for left and center DCA operation with electromagnet currents of $0 \mathrm{~A}, 5 \mathrm{~A}$, and $10 \mathrm{~A}$. RPA-DC data are not obtained for the right DCA operational configuration. Electrical connectivity of the DC is also investigated by either isolating the RPA$\mathrm{DC}$ or connecting it to the TA. a)
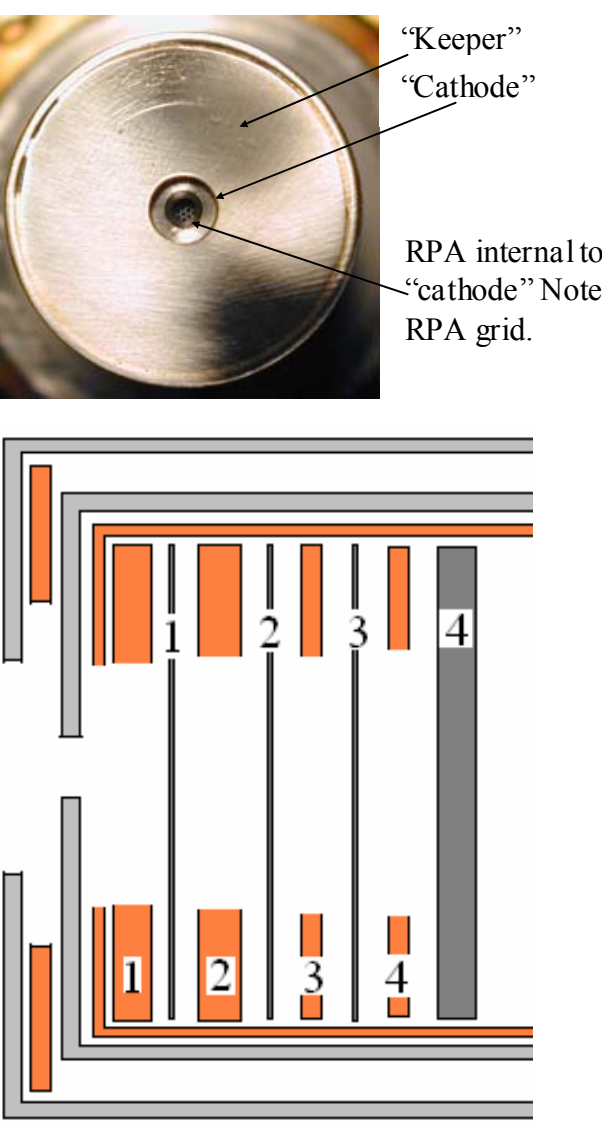

"Keeper" and "Cathode"

RPA Grids and Collector

\section{Boron Nitride Insulator}

Figure 5: a) Photograph of the RPA-DC. b) Schematic of the RPA-DC.

\begin{tabular}{|cc|}
\hline Spacer & Thickness (mm) \\
\hline 1 & 3.4 \\
2 & 3.4 \\
3 & 1.0 \\
4 & 1.0 \\
\hline \multicolumn{3}{|c|}{ Potential w.r.t. } \\
Grid & Cathode Comm (V) \\
\hline 1 & Float \\
2 & -25 \\
3 & -25 to 45 \\
4 & Collector $-25 \mathrm{~V}$ \\
\hline
\end{tabular}

Table 1: RPA spacer dimensions and grid setup. 


\section{Data Acquisition Systems}

The majority of the experiments presented here rely heavily upon obtaining I-V characteristics with Langmuir probes. Specifically the 5PLP-DC, 7PLP-DC, APLP-DC, and ACLP-DC utilize Langmuir probe diagnostics and are discussed first. The RPA-DC setup is slightly different and is explained last.

Both the 5PLP-DC and 7PLP-DC utilize the same data acquisition setup. As previously mentioned, each probe is connected to a biasing power supply through a $100 \mathrm{Ohm}$ shunt resistor. In this case the biasing power supply is a Sorensen DLM 60-10 power supply that is remotely voltage-controlled using a Keithley 2410 sourcemeter. The sourcemeter alone is unable to bias the probes due to a power limitation. Each probe is biased with respect to ground during data collection, but bias voltages are presented with respect to cathode common by subtracting the TA cathode common bias during post-processing. (Recall that during simulated operation, cathode common is biased $+25 \mathrm{~V}$ with respect to ground.) A 34970A 22-bit Agilent data logger with 2 - 34901A 20-channel multiplexers is utilized to measure the voltage drop across the shunt resistors. This entire setup is controlled through a LabView interface. LabView sets the power supply bias voltage through the sourcemeter and then measures the shunt voltage drop with the data logger. Data are acquired in approximately $0.6 \mathrm{~V}$ increments over a $61 \mathrm{~V}$ range and one sweep requires approximately 6 minutes. A total of 42 sweeps are acquired resulting in 348 total I-V characteristics for the 5PLP-DCs and 7PLP-DCs analyses.

APLP-DC and ACLP-DC data acquisition setups are nearly identical. Axial probe position is controlled using a stepper motor controlled NEAT RMS-800 translation stage mounted with a custom-made probe alignment stand. A National Instruments NuDrive 4SX-411 amplifier powers the stepper motor and control of the table is provided by a National Instruments PCI-7344 stepper controller. The probe alignment stand simplifies probe positioning because the $\mathrm{x}, \mathrm{y}$, and $\mathrm{z}$ probe axes are adjusted independent of the translation stage location with respect to the TA. This setup greatly reduces the time required to align each probe with the DC "cathode" guide tube and "cathode" orifice. During APLP-DC data acquisition two probes are utilized simultaneously at either the center and right locations or the left and right locations depending on DCA activity. Only a single probe is utilized during ACLP-DC data acquisition. Probe I-V characteristics are acquired utilizing a Keithley 2410 sourcemeter. The sourcemeter sets the probe bias and then measures both the bias and the collected current. Positioning and data acquisition are controlled through a LabView interface. LabView sets the probe position through the NuDrive and acquires the data with the sourcemeter. Data are acquired in $0.5 \mathrm{~V}$ increments over a $60 \mathrm{~V}$ range and one sweep requires approximately 20 seconds. A total of approximately $1200 \mathrm{I}-\mathrm{V}$ characteristics are obtained for the APLP-DC and ACLP-DC.

The RPA-DC data acquisition setup is designed to measure the collector current as a function of the ion retarding grid potential. Grid 2 is held at a constant $-25 \mathrm{~V}$ with respect to cathode common by connecting the grid to ground. Grid 3 is swept from $-25 \mathrm{~V}$ to $45 \mathrm{~V}$ with respect to cathode common $(0-70 \mathrm{~V}$ with respect to ground) by a Keithley 2410 sourcemeter. Collector current is monitored using a Keithley 486 picoammeter that is connected to ground. Data acquisition is controlled through a LabView interface that changes the sourcemeter output voltage while recording the picoammeter current. Each sweep consists of $1000 \mathrm{I}-\mathrm{V}$ pairs and requires approximately 6 minutes. Averaging multiple sweeps is found to reduce the noise associated with data collection so three sweeps are obtained for most operating conditions. Obtaining more than three sweeps at a given operating condition is impractical due to time constraints.

\section{Analysis Methods}

\section{A. Langmuir Probe}

Langmuir probe I-V characteristics are typically analyzed based on either a thin sheath or orbital motion limited (OML) assumption. A thin sheath analysis is applied to all Langmuir probes presented in this paper and an OML analysis is applied to the ACLP-DC when the probe is internal to the DC. An attempt at analyzing the data based on a dual primary-maxwellian electron population is also described.

\section{Thin Sheath}

Langmuir probes are typically sized such that the probe operates in the thin sheath regime. Ion thruster discharge plasma number density and electron temperature are expected to have values within the range of $10^{10}-10^{12} \mathrm{~cm}^{-3}$ and $2-13 \mathrm{eV},{ }^{23-25}$ respectively. The relationship of the Debye length to electron number density and temperature is illustrated in the following equation. 


$$
\lambda_{D}=743 \sqrt{\frac{T_{e}[\mathrm{eV}]}{n_{e}\left[\mathrm{~cm}^{-3}\right]}}
$$

In the thin sheath regime, the flux of particles entering the sheath can be calculated without considering the details of the orbits of these particles in the sheath. ${ }^{20}$ For a large ratio of probe radius, $r$, to Debye length, $\lambda_{\mathrm{D}}$, the collection area of the probe can be approximated as the area of the probe. ${ }^{20} \mathrm{~A}$ large probe radius helps to minimize edge effects for planar probes (5PLP-DC, 7PLP-DC, and APLP-DC) and a large ratio of length to radius minimizes end effects for cylindrical probes (ACLP-DC).

Because there are over $1500 \mathrm{I}-\mathrm{V}$ characteristics to analyze, the software IGOR Pro by WaveMetrics, Inc. is utilized to analyze the data. IGOR loads the data files containing I-V pairs of data for each of the probe sweeps and then applies a thin sheath data analysis. Initially the floating potential is determined by locating the voltage value corresponding to zero current. Plasma potential is then calculated by finding the maximum in the derivative of the I$\mathrm{V}$ curve. Based on the floating potential and plasma potential, IGOR determines the electron retarding region of the probe trace and attempts to fit a line to the natural log of the electron current versus voltage data. The fit is made progressively better by removing I-V data pairs from the beginning and end of the electron retarding region. This procedure is repeated until a specified chi-squared parameter for the fit is achieved. The procedure loop is also plotted so that the user can visually validate the fit being obtained. Electron temperature is then calculated as the inverse of the slope of the log-linear I-V curve. The measured ion saturation current, electron temperature, and Bohm approximation for ion velocity ${ }^{26}$ readily give the ion number density by Equation 2 .

$$
I_{s i}=0.61 e n_{i} \sqrt{\frac{e T_{e}}{M_{i}}} A_{p}
$$

In this equation, $T_{e}$ is electron temperature $(\mathrm{eV}), \mathrm{e}$ is the elementary charge $\left(1.6 \times 10^{-19} \mathrm{C}\right), \mathrm{A}_{\mathrm{p}}$ is the probe area $\left(\mathrm{m}^{2}\right)$, $I_{\mathrm{si}}$ is the ion saturation current $(\mathrm{A}), \mathrm{n}_{\mathrm{i}}$ is ion number density $\left(\mathrm{m}^{-3}\right)$ and $\mathrm{M}_{\mathrm{i}}$ is the ion mass $\left(\mathrm{M}_{\mathrm{Xe}}=2.18 \mathrm{e}-25 \mathrm{~kg}\right)$

\section{Orbital Motion Limited (OML)}

In the OML or "thick-sheath" regime the sheath dimensions and orbits of particles entering the sheath must be considered. This regime is analyzed by the techniques developed by Laframboise, ${ }^{27}$ which assumes a cylindrical probe immersed in a cold, collisionless, stationary plasma. In this case, the sheath dimensions are assumed to increase with probe bias such that the collected ion current is affected. Ion current collected by a probe biased below the floating potential is defined by Equation $3 .{ }^{27}$

$$
I_{i}=\xi e n_{i} \sqrt{\frac{e T_{e}}{2 \pi M_{i}}} A_{p}
$$

In this equation, $\xi$ is a dimensionless current correction developed by Laframboise that depends on probe size, plasma number density, and temperature. For the temperatures and number densities obtained in most ion thruster plasmas, Steinbrüchel suggests that $\xi$ is given to within 3\% error by Equation $4 .{ }^{28}$

$$
\xi=\sqrt{\frac{1.27 V}{T_{e}}}
$$

Combining Equations 3 and 4 allows $\mathrm{I}^{2}$ to be plotted as a linear function of $\mathrm{V}$ and the ion number density can then be calculated as a function of the slope of $\mathrm{I}^{2}$ versus $\mathrm{V}$ as illustrated in Equation 5.

$$
n_{i}=\frac{1}{A_{p}} \sqrt{\left(d I_{i}^{2} / d V\right) \frac{2 \pi M_{i}}{1.27 e^{3}}}
$$

In this equation, $n_{i}$ is ion number density $\left(m^{-3}\right), A_{p}$ is probe area $\left(m^{2}\right), I_{i}$ is ion current $(A), V$ is probe voltage $(V), M_{i}$ is ion mass $(\mathrm{kg})$, and e is the elementary charge $\left(1.6 \times 10^{-19} \mathrm{C}\right)$. 
Chen suggests that the OML regime is entered when the ratio of probe radius to Debye length is less than approximately three. ${ }^{29}$ Since only the number density calculation changes in this OML analysis, the IGOR thin sheath analysis described above is augmented to contain an OML option. The thin sheath analysis is initially blindly applied, however, if the Debye length is calculated to be less than a third of the probe radius the OML number density calculation is utilized. An OML calculation is unnecessary for a planar probe, ${ }^{29,30}$ so only the ACLP-DC results are subjected to the OML subroutine option. More discussion about the ACLP-DC axial locations over which OML theory is necessary is discussed in the results section.

\section{Primary-Maxwellian Electron Population}

In addition to the thin sheath and OML analyses described above, a dual primary-Maxwellian electron population analysis is also attempted. In plasma consisting of primary and Maxwellian electrons, the current to a biased Langmuir probe can be represented by Equation $6 .^{31}$

$$
I=B_{1}+B_{2} V+B_{3} \exp \left(B_{4} V\right)
$$

In this equation primary and Maxwellian electron current are represented by the linear and exponential terms, respectively. The $B_{i}$ coefficients can be numerically determined from a least-squares differential-correction technique utilizing the electron retarding region of the experimental data and the plasma properties calculated based on these coefficients. ${ }^{31}$

Unfortunately the dual population analysis is unable to be successfully applied to the data presented. The numerically determined coefficients are found to be extremely sensitive to the initial conditions. Specifically the experimental data voltage range can significantly affect the sign and magnitude of the $\mathrm{B}_{1}$ and $\mathrm{B}_{2}$ values. For instance removing one I-V data pair from the electron retarding region can cause the calculated primary electron energy to fluctuate from $30 \mathrm{~V}$ to $10 \mathrm{~V}$ and the primary electron current contribution to become negative. This result is inconsistent with that presented by Beattie, ${ }^{31}$ who found that calculated plasma properties were insensitive to the range of the electron retarding region utilized to determine the coefficients. He also suggests that a $20-25 \mathrm{~V}$ data range with a maximum $1 \mathrm{~V}$ increment be used to minimize the sensitivity of the calculated coefficients to noise within the data, a requirement satisfied by the data presented.

The sensitivity described may be caused by a variety of reasons, for example: 1) there are no primaries present at the DC locations, 2) the primary current is orders of magnitude smaller than the maxwellian current, which may explain why the coefficients associated with the linear primary electron current $\left(\mathrm{B}_{1}\right.$ and $\left.\mathrm{B}_{2}\right)$ are so sensitive, 3$)$ there may be too much noise in the data, 4) the voltage range is too small, $20 \mathrm{~V}$ is near the edge of the range suggested by Beattie, 5) Beattie utilized a mercury ion thruster plasma for his analyses, primary electrons may not be as easily detected with this method in the TA xenon plasma. It is important to note that Herman has also had difficulty applying this analysis to the NSTAR discharge plasma. ${ }^{23}$

\section{B. Retarding Potential Analyzer (RPA)}

A RPA is utilized internal to a DC in order to analyze ion voltage distributions at the dormant cathode locations. In an RPA a series of grids are utilized to selectively filter ions depending on their energy-to-charge ratios. Specifically the derivative of the resulting I-V characteristic is proportional to the ion voltage distribution function as illustrated in Equation 7. ${ }^{12,21}$

$$
\frac{d I}{d V}=-\frac{Z_{i}^{2} e^{2} n_{i} A_{c}}{M_{i}} f(V)
$$

In this equation $Z_{\mathrm{i}}$ is the charge-state of the ion, $\mathrm{e}$ is the elementary charge, $n_{i}$ is the ion density, $A_{c}$ is the collection area, $f(V)$ is the ion voltage distribution function, and $\mathrm{M}_{\mathrm{i}}$ is the ion mass. Of primary importance for the research presented here is the voltage value for the peak in the distribution function, otherwise known as the most-probablevoltage. Because the acquired raw data has enough noise to make the derivative meaningless, a certain

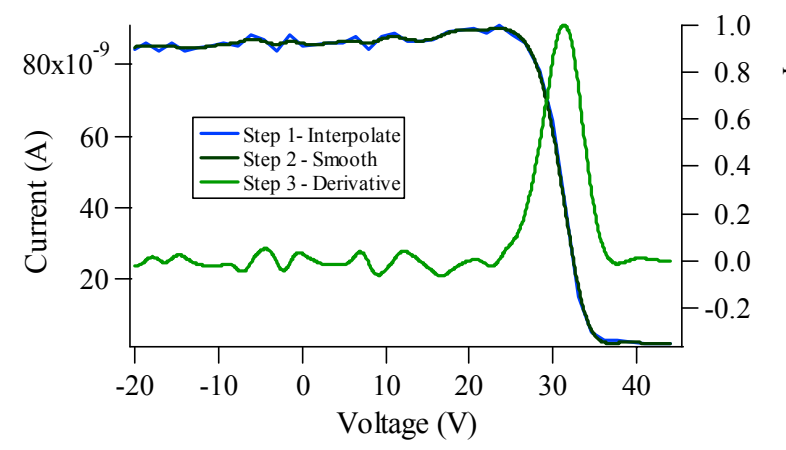

Figure 6: Example retarding potential analyzer (RPA) analysis routine results.

American Institute of Aeronautics and Astronautics 
amount of averaging, data interpolation, and smoothing is required

Three RPA data sweeps are obtained for each operational configuration and averaged in order to reduce noise associated with these data. The data analysis routine is then applied utilizing an IGOR 4.0 function that 1) interpolates, 2) smoothes, 3) takes the derivative, and 4) determines the most-probable-voltage. Each interpolated I$\mathrm{V}$ data pair is determined by linearly interpolating the preceding and following experimental data pair. Next, the interpolated data are smoothed utilizing a smoothing spline that is based on the algorithm described by Reinsche, ${ }^{32}$ that requires a user-defined filter factor to determine the amount of smoothing. Next, the derivative of the smoothed data is taken to determine the ion voltage distribution function (i.e, the E/q distribution function). The last step in the RPA data analysis routine is to find the most-probable-voltage associated with each operating condition by determining the voltage at which the peak in the distribution function occurs.

For the data presented here various levels of smoothing are required ranging from a filter factor of 0.05 (less smoothing) to 0.5 (more smoothing) depending on the noise in the data. Filter factors are determined on a trial and error basis by visually watching the output profiles as shown in Figure 6. The filter factor is increased until a discernable derivative is obtained.

\section{Results}

\section{A. 5PLP-DC \& 7PLP-DC}

The following sections describe the results obtained utilizing the 5PLP-DCs and 7PLP-DCs for left, center, and right DCA operation with electromagnet currents of $0 \mathrm{~A}, 5 \mathrm{~A}$, and $10 \mathrm{~A}$. The DCs are also operated electrically connected and electrically isolated (disconnected) from the TA as described in Section II above. Figure 7 shows typical results for the 5PLP-DCs. Results are shown from the perspective of a viewer looking downstream from behind the TA as shown in the coordinate system in Section II. In each figure three different TA configurations are shown and for each configuration the three circles represent the three cathodes, one active cathode and two DCs. Each colored dot inside the circles represents one of the PLPs. All voltages are referenced with respect to cathode common.

Typical measured floating voltages are between 2-14 V above cathode potential with floating voltage increasing with electromagnet current. For the nominal operating condition of $0 \mathrm{~A}$ electromagnet current, floating voltages are on average $5 \mathrm{~V}$ above cathode potential. Connecting or disconnecting the DCs has no noticeable effect on floating voltage. No noticeable trend between DCA location and measured floating potential is determined.

Measured electron temperatures are typically within a 3-6 eV range with electron temperature decreasing with increasing electromagnet current. The nominal operating condition shows electron temperatures between 4-6 eV. Operation with the DCs connected shows slightly lower electron temperatures than disconnected operation. However, these differences are only on the order of $3 \%$ and could be accounted for by probe and analysis error. Right and center DCA configurations show higher electron temperatures on the left side of the TA, and this difference decreases with increasing electromagnet current.

Plasma potentials are measured between 27-33 V with plasma potential increasing with increasing electromagnet current. The nominal operating condition of 0 A electromagnet current shows plasma potentials approximately 2-5 $\mathrm{V}$ above the discharge voltage. Measured plasma potential is typically higher for the right DCA active configurations, specifically configuration 10RC and 10RI. No noticeable difference is apparent when the DCs are electrically connected to or isolated from the TA.

Measured number densities are between $8.9 \times 10^{10}-2.5 \times 10^{11} \mathrm{~cm}^{-3}$ with number density decreasing with increasing electromagnet current. For the nominal configuration number densities are consistently $1.3 \times 10^{11}-$ $2.5 \times 10^{11} \mathrm{~cm}^{-3}$. No noticeable difference is apparent when the DCs are electrically connected to or isolated from the TA.

Finally the Debye length is calculated based on the number density and electron temperature. Values are typically on the order of $5 \times 10^{-3} \mathrm{~cm}$ or less, which indicates that the 5PLP-DC probes have a ratio of probe radius to Debye length on the order of 16 .

Although the configurations with the center DCA active (0MC, 5MC, 10MC, 0MI, 5MI, 10MI) are symmetric, plasma properties measured on the right and left side of the DCA differ. Specifically, number densities on the left side are approximately $50 \%$ larger than the right side for a $0 \mathrm{~A}$ electromagnet current. This difference decreases with increasing electromagnet current. The same trend is seen when analyzing electron temperature.

The discrepancies described above are within the error of the number density measurements, which are expected to be $\sim 50 \%,{ }^{33}$ but they may also be explained if the plasma is coupling unevenly inside the TA. Asymmetries in the magnetic field may cause the plasma to be non-uniform and subsequently denser in regions of lower magnetic field 

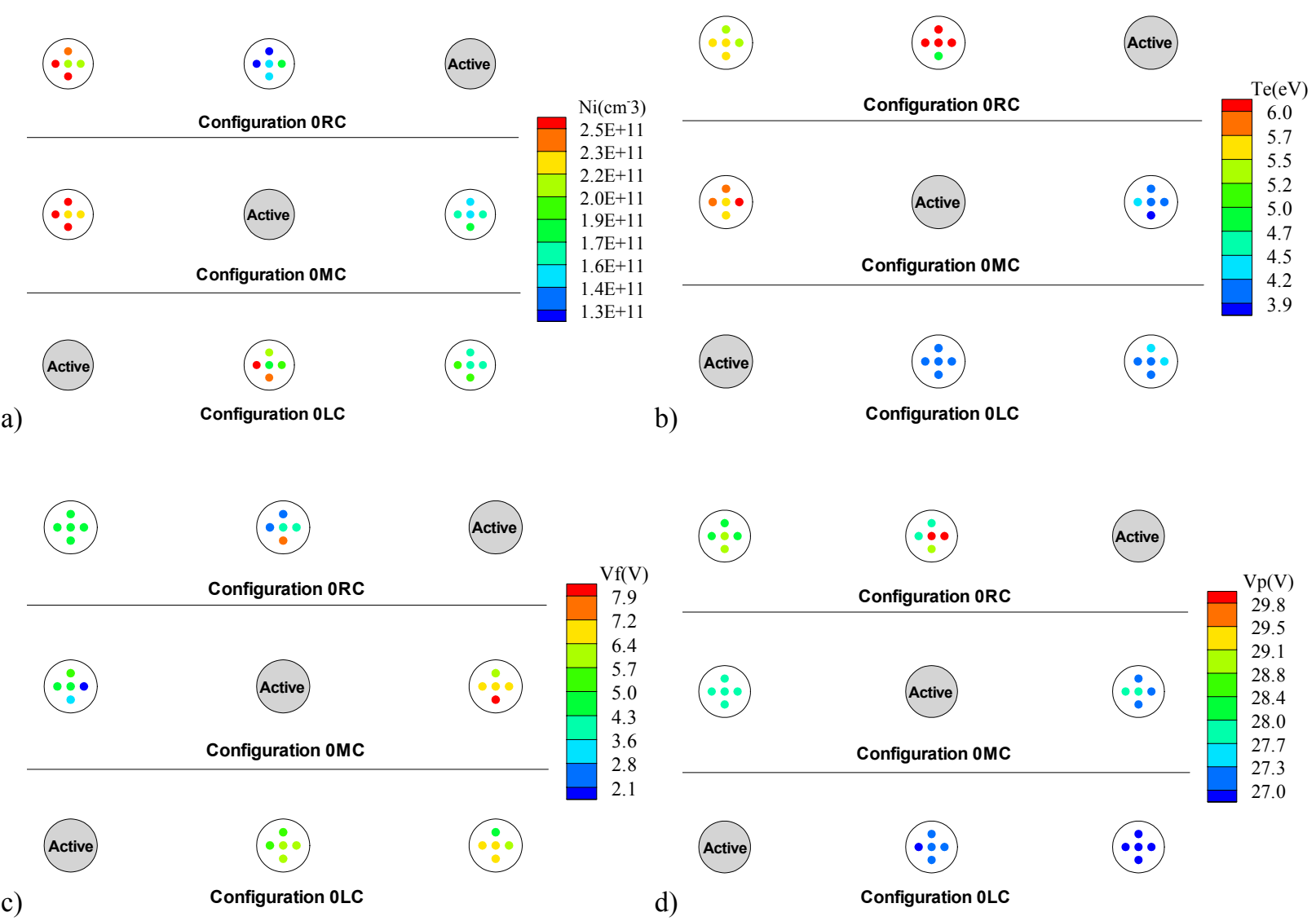

Figure 7: 5PLP-DC plasma properties for the 0 A electromagnet DC connected configuration. a) Number density b) Electron temperature c) Floating potential d) Plasma potential

strength. This may explain the dependence of these results on electromagnet current and subsequently the magnetic field. As electromagnet current increases the magnetic field increases causing perhaps one or both of the following to occur. 1) Increasing the magnetic field strength causes it to become more uniform making the relative difference between the left and right DCs to decrease; or 2) as the backplate magnetic field increases the plasma is pushed downstream, a trend that has been documented by other researchers, ${ }^{18,34,35}$ causing the relative difference between the left and right DCs to decrease. Magnetic field mapping of the TA prior to experimental testing did not show any asymmetry in the magnetic field, ${ }^{18}$ however, the effect of changing the magnetic field on the relative number density between the left and right DC locations during center DCA operation cannot be ignored.

Another interesting result is that configurations with the left DCA active and those with the right DCA active are not symmetrical as expected. Results have maximum differences on the order of $\sim 50 \%, \sim 50 \%$, and $\sim 10 \%$ for number density, electron temperature, and plasma potential, respectively. The right DCA active configurations have larger values of plasma potential and electron temperature. These discrepancies are expected to be within the error of the methods applied here and the explanations developed above regarding the magnetic field may apply for these configurations as well. Another explanation may be the $\sim 1 \mathrm{~V}$ increase in discharge voltage for right DCA active configurations. An increase in discharge voltage may explain the increase in plasma potential, as well as the increase in number density and electron temperature.

\section{B. APLP-DC \& ACLP-DC}

The APLP-DC and ACLP-DC are utilized for a left active and center active DCA with electromagnet currents of $0 \mathrm{~A}, 5 \mathrm{~A}$, and $10 \mathrm{~A}$. Data are not obtained for the right active DCA configuration due to time constraints. For the ACLP-DC, data are only obtained at the left location during center DCA operation and at the center location during left DCA operation. Typical raw data profiles are shown in Figure 8. When the probe is external to the DC, the I-V characteristic appears as expected. As the probe moves internal to the DC, the collected current significantly decreases leading to an almost linear I-V characteristic with small slope. The decrease in probe signal leads to a 
smaller signal-to-noise ratio and as a result the thin sheath analysis procedure described above is unable to calculate the plasma parameters. Internal to the DC, I-V characteristic derivatives become meaningless and the log-linear current versus voltage plot can no longer be used to obtain the electron temperature. However, because the ACLPDC has a larger collection area than the APLP-DC, slightly better trends are able to be determined.

Figures 9 - 11 show axial plasma properties for the APLP-DC and ACLP-DC for various TA operational configurations. All voltages are referenced with respect to cathode common. An axial position of zero corresponds to the external side of the "cathode" orifice. For the ACLP-DC, positions are measured from the tungsten wire-alumina sleeve interface and certainty in axial position is $\sim 3 \mathrm{~mm}$. Because the number density decreases as the probe moves internal, the ACLP-DC transition to the OML regime is determined to occur at $\sim 3 \mathrm{~mm}$ internal to the DC. As shown by the figures, as the probe moves internal to the DC (negative axial positions) the data becomes noisier and general trends become more difficult to establish. Data are taken at smaller axial increments closer to the "cathode" and
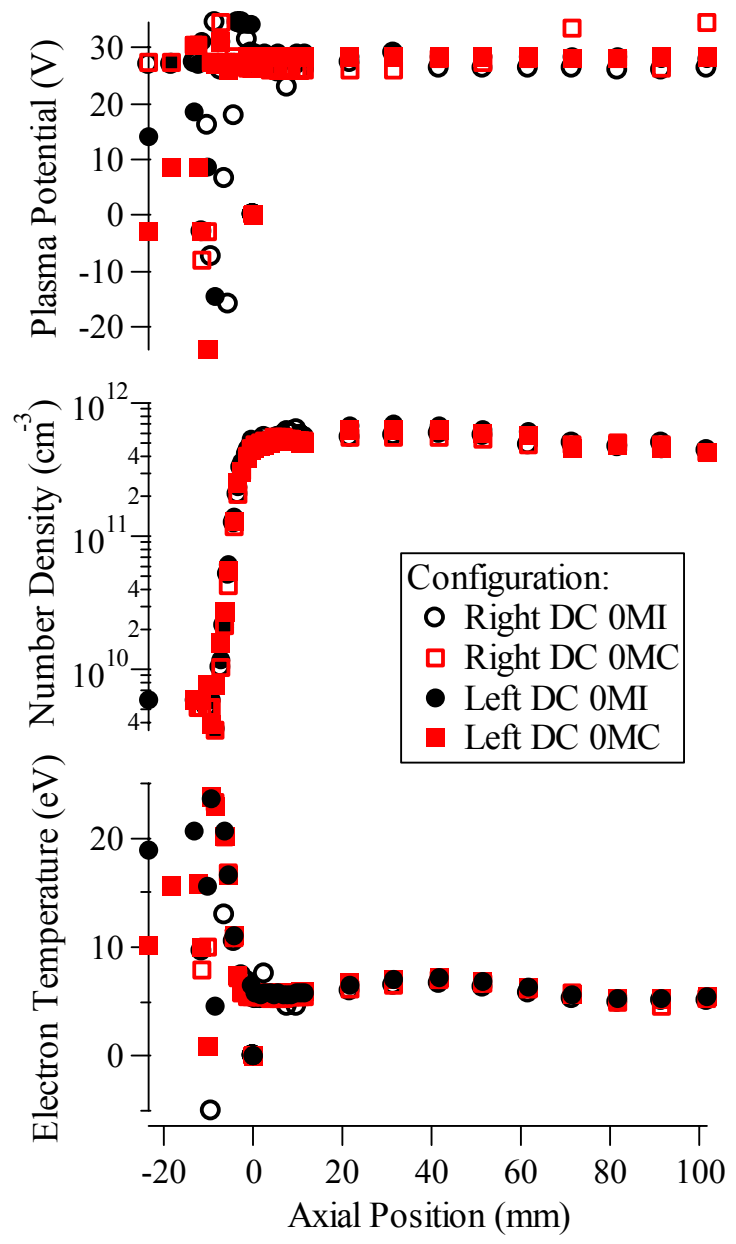

Figure 9: Axial plasma parameters for the left and right APLP-DC for the center DCA active 0 A configuration.

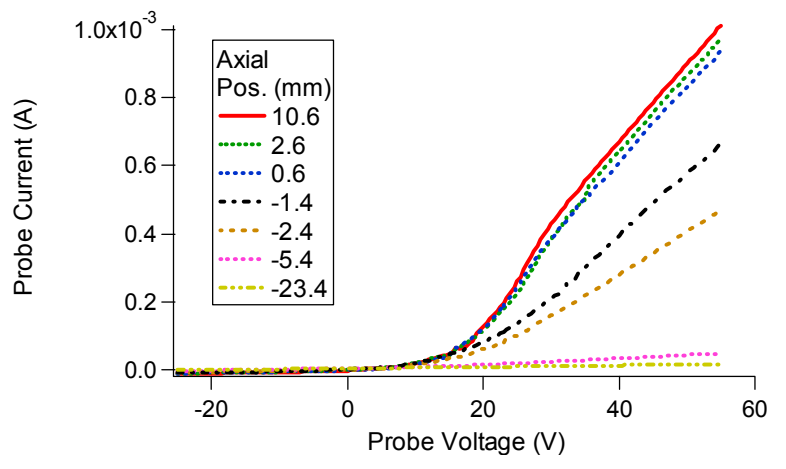

Figure 8: Typical APLP-DC raw data I-V characteristics as a function of axial position. As the probe moves inside the $\mathrm{DC}$, the probe current significantly decreases.
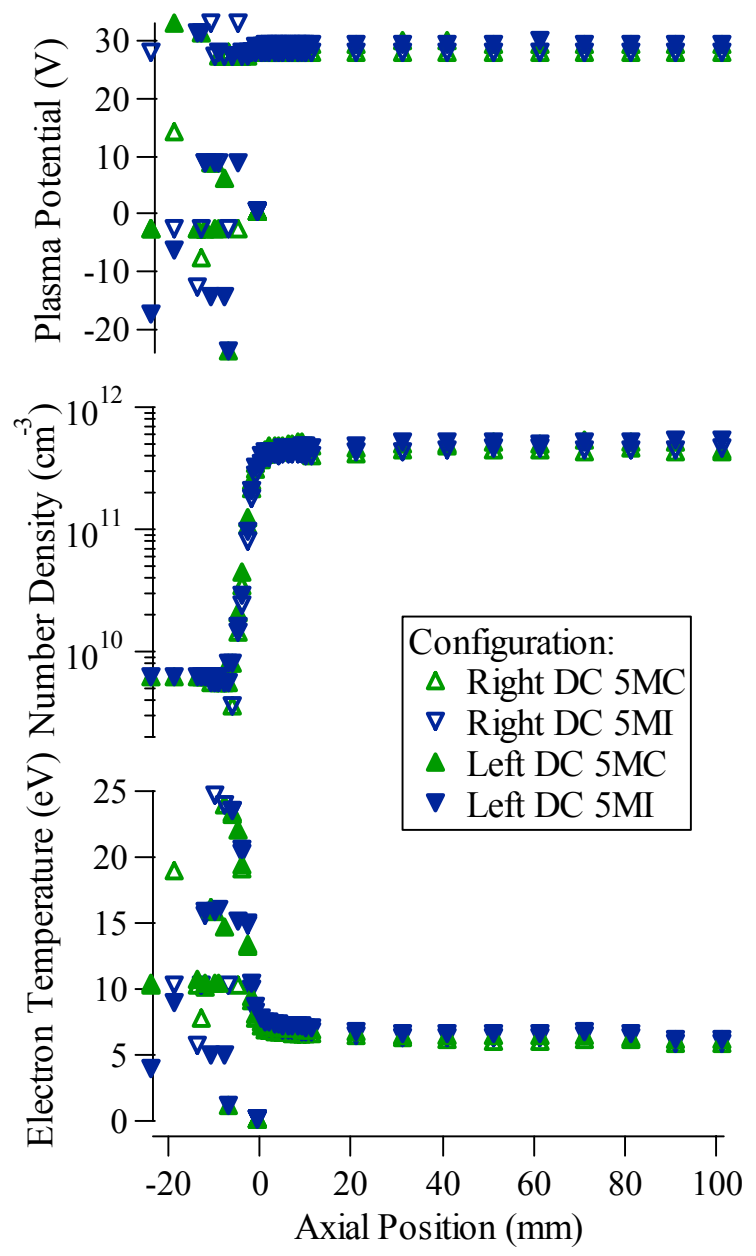

Figure 10: Axial plasma parameters for the left and right APLP-DC for the center DCA active 5 A configuration. 
"keeper" orifices in an attempt to visualize the DC sheath structure; however, no clear structure is evident.

Electron temperature values are typically between 3-8 eV external to the DC and appear to increase internal to the DC. As the electromagnet current increases, electron temperature decreases and this trend becomes more apparent at the "cathode" exit plane $\left(\begin{array}{lll}0 & \mathrm{~mm}\end{array}\right)$. Electrical connectivity of the DCs does not have a noticeable effect on the axial electron temperature profile. Data obtained at the right and left locations during center DCA operation and at the center and right locations during left DCA operation do not show significant differences and are typically within 0.5 $\mathrm{eV}$. For the nominal 0 A electromagnet configuration, electron temperatures are typically 5 $\mathrm{eV}$, which is consistent with data obtained by the 5PLP-DCs and 7PLP-DCs.

Plasma potential values are typically between 26-32 V (2-4 V above the discharge voltage) external to the DC, but internal to the DC the plasma potential data become extremely noisy. No noticeable trend is discernable internal to the DC because of the linear I-V characteristic phenomena described above. External to the DC the plasma potential remains relatively constant and increases with electromagnet current. Electrical connectivity of the DC has no noticeable effect on the axial

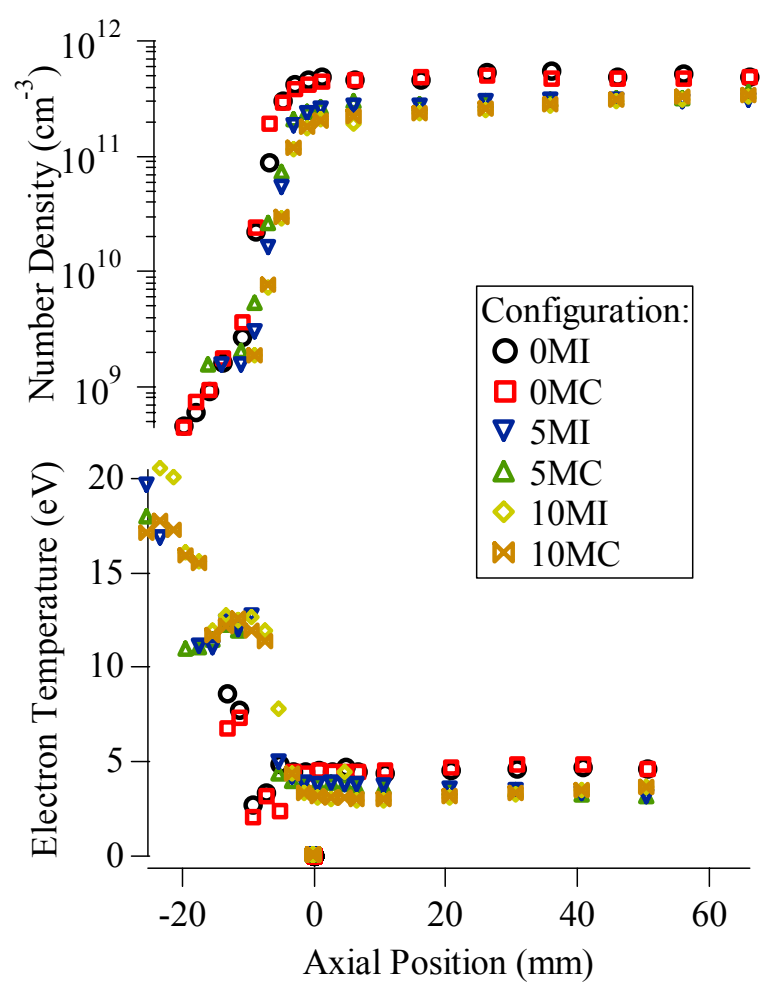

Figure 11: Axial plasma parameters for the left ACLPDC with the center DCA active. plasma potential profile. Data obtained at the right and left locations during center DCA operation and at the center and right locations during left DCA operation do not show significant differences and are typically within $\sim 1 \mathrm{~V}$ of each other.

Number densities are typically on the order of $5.0 \times 10^{11} \mathrm{~cm}^{-3}$, which is slightly larger than data obtained with the 5PLP-DCs and 7PLP-DCs, but within $~ 45 \%$. As electromagnet current increases, number density values decrease and this trend is especially apparent near the "cathode" exit plane $(0 \mathrm{~mm})$. DC electrical connectivity does not have a noticeable effect on axial number density profiles. When the center DCA is active, the left APLP-DC typically measures number densities $\sim 10 \%$ larger than the right APLP-DC. This trend is consistent with the 5PLP-DC and 7PLP-DC data. When the left DCA is active, the center and right APLP-DCs measure approximately the same number densities. Finally, as the probe moves internal to the DC, the number density decreases by two orders of magnitude within $5 \mathrm{~mm}$.

Floating potentials are measured by the APLP-DC to be lower than expected and are on the order of $-2.5-5 \mathrm{~V}$ relative to cathode common, a result inconsistent with the 5PLP-DC and 7PLP-DC data. However, the ACLP-DC measures floating potentials in the range of 3-12 V above cathode potential, as expected. The lower floating potentials measured by the APLP-DC are attributed to the probe and are believed unrelated to the TA plasma. The floating potential discrepancy may be explained by magnetic field effects. Because electrons are orbiting the TA magnetic field lines with radius equal to the Larmor radius, the planar probe primarily collects the velocity component parallel to the field lines where as the cylindrical probe collects the perpendicular component.

A summary of trends associated with the APLP-DC and ACLP-DC are as follows: 1) Electrical connectivity of the DCs does not affect axial plasma property profiles, 2) as the electromagnet current increases (backplate magnetic field increases) plasma potential increases, where as electron temperature and number density decrease, 3) number density decreases two orders of magnitude within $5 \mathrm{~mm}$ internal to the $\mathrm{DC}$, and 4) data obtained internal to the DC are more difficult to analyze due to a decrease in signal-to-noise ratio. In general, the trends determined with the Langmuir probe DCs (5PLP-DC, 7PLP-DC, APLP-DC, ACLP-DC) are quite similar, thus increasing the confidence in these measurements. 


\section{RPA-DC}

The RPA-DC is utilized for a left active and center active DCA with electromagnet currents of $0 \mathrm{~A}, 5 \mathrm{~A}$, and 10 A. RPA-DC data are not obtained for the right active DCA configuration. A voltage sweep of $70 \mathrm{~V}$ is utilized because increasing the sweep to $200 \mathrm{~V}$ does not reveal interesting structures. Figure 12 shows the peak $\mathrm{E} / \mathrm{q}$ in the distribution function (most-probable-voltage) as a function of the TA configuration for the center active DCA. All voltages are referenced with respect to cathode common. Typical trends show the mostprobable-voltage increasing with increasing electromagnet current. Most-probable-voltage values range from $18-32 \mathrm{~V}$ above cathode common. No trends with the ion voltage distribution function other than most-probable-voltage are noticed. This may be a result of the noise in the RPA-DC raw data, which becomes amplified when taking a derivative.

Except for the right DC during left DCA operation, measured most-probable-voltages are larger than the discharge voltage and are similar to the plasma potential.

As mentioned above, the plasma potential at the DC locations increases with increasing electromagnet current, a trend also noticed with the RPA-DC most-probable-voltage. These results are consistent with ions falling through the plasma potential to reach the RPA collector. Results also show voltages greater than or equal to $30 \mathrm{~V}$, which is cause for concern, especially if there is a significant population of doubly-charged ions present. Some of these ions are expected to be impacting the dormant cathode and, if a significant doubly-charged ion population exists, causing erosion of the dormant cathode. These energetic ions may also be impacting the active DCA and causing the familiar erosion patterns seen during wear-testing, ${ }^{7,8,36,37}$ especially if a significant doubly-charged ion population exists.

\section{Erosion Analysis}

In the following section the plasma properties described above are utilized to predict the potential erosion of the dormant cathodes for both Molybdenum (Mo) and Carbon graphite keeper materials. Currently, most DCA keepers are constructed of Mo, but different materials with lower sputtering yields, such as graphite, are being investigated. ${ }^{9}$ In order to predict the erosion of the dormant cathodes an accurate sputtering yield model for low-energy xenon ions bombarding the keeper is required. Unfortunately, many models have been developed and no one model appears to be superior. Both Duchemin ${ }^{38}$ and Nakles $^{39}$ have illustrated the uncertainty in sputtering yield and theory near threshold. For the analysis that follows, an erosion model is developed based on experimental data and sputtering theory. The output of the model is sputter yield calculated as a function of bombarding ion energy and ion incidence angle. Erosion rate is then calculated based on the output sputter yield.

Sputtering energy threshold as a function of incidence angle is assumed to be of the form described by Yamamura. ${ }^{40}$ For small angles the sputtering process dominates and Yamamura suggests the following relation.

$$
E_{t h}(\theta)=E_{s}\left[4.4-1.3 \log \left(m_{2} / m_{1}\right)\right] \cos ^{2}(\theta)
$$

In this equation, $\mathrm{E}_{\mathrm{s}}$ is sublimation energy $(\mathrm{eV}), \mathrm{m}_{1}$ and $\mathrm{m}_{2}$ are the incident and target atom mass (kg/atom), respectively, and $\theta$ is the angle of incidence (degrees). Herman ${ }^{41}$ and Williams ${ }^{42}$ suggest bombarding ions have presheath angles on the order of $60 \mathrm{deg}$, resulting in impacting angles of $\sim 35 \mathrm{deg}$. or less with respect to keeper normal. Equation 8 is used to determine Mo and graphite sputtering threshold energy as a function of angle of incidence for angles less than $40 \mathrm{deg}$. These results are presented in Figure 13. Sputtering yields are calculated by adjusting the equation developed by Wilhelm ${ }^{43}$ to account for both bombarding ion energy and incidence angle as illustrated in Equation 9.

$$
Y(E, \theta)=K\left(E-E_{t h}(\theta)\right)^{2} \quad \text { [atoms/ion] }
$$




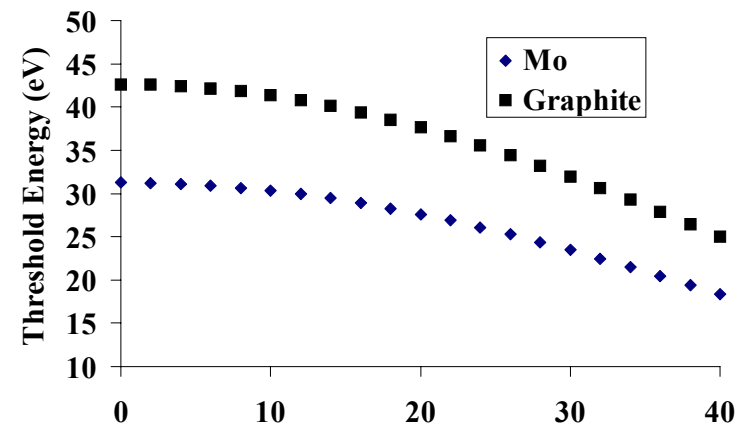

a)

b)

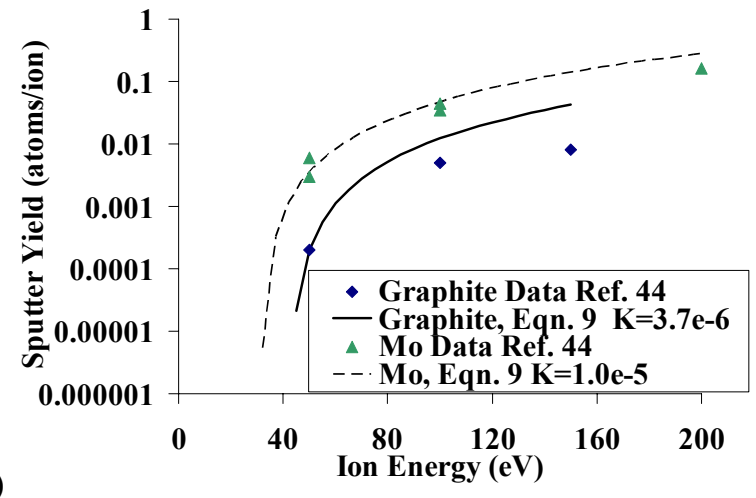

Figure 13: a) Graphite and molybdenum threshold energy as a function of angle of incidence. b) Equation 9 fit to Doerner et al. molybdenum and graphite sputter yield weight loss data for normal ion incidence.

\begin{tabular}{|c|c|c|c|}
\hline & Xenon & Molybdenum & Graphite \\
\hline$\rho_{2}\left(\mathrm{~kg} / \mathrm{m}^{3}\right)$ & $\mathrm{N} / \mathrm{A}$ & 10280 & 2274 \\
\hline $\mathrm{m}_{1}$ (kg/atom) & $2.18 \mathrm{E}-25$ & $\mathrm{~N} / \mathrm{A}$ & $\mathrm{N} / \mathrm{A}$ \\
\hline $\mathrm{m}_{2}$ (kg/atom) & $\mathrm{N} / \mathrm{A}$ & $1.59 \mathrm{E}-25$ & $2.00 \mathrm{E}-26$ \\
\hline $\mathrm{E}_{\mathrm{s}}(\mathrm{eV})^{45,46}$ & $\mathrm{~N} / \mathrm{A}$ & 6.83 & 7.41 \\
\hline $\mathrm{K}$ in Eqn. 9 & $\mathrm{~N} / \mathrm{A}$ & $1.0 \mathrm{E}-5$ & $3.7 \mathrm{E}-6$ \\
\hline
\end{tabular}

Table 2: Input parameters for erosion model.

In this equation $\mathrm{E}$ is the ion energy $(\mathrm{eV})$ and $\mathrm{K}$ is a constant. Doerner et $a l^{44}$ have measured sputter yields for normal incident xenon bombarding graphite and Mo using a weight loss detection scheme. A curve fit of Equation 9 assuming normal incident ions to the measured Mo and graphite sputter yield data is shown in Figure 13. The fits yield $\mathrm{K}$ values of $3.7 \times 10^{-6}$ and $1.0 \times 10^{-5}$ for the graphite and Mo data, respectively. Although these $\mathrm{K}$-values are for normal incident ions they are also utilized for off-normal incidence. Each fit is made to have better agreement with the low-energy data because low-energy sputtering is of primary interest for this analysis.

Ion energy is calculated assuming an initially stationary ion falling through the potential difference between the plasma and keeper, as illustrated by Equation 10. In this equation, $\mathrm{V}_{\mathrm{p}}$ is the plasma potential, and $\mathrm{V}_{\mathrm{k}}$ is the keeper potential. Keeper potential is typically on the order of $4 \mathrm{~V}$ and is assumed constant for this analysis. Equation 11 represents the flux of ions required to produce a given rate of erosion.

$$
\begin{array}{cc}
E=\left(V_{p}-V_{k}\right) & {[\mathrm{eV}]} \\
\Gamma_{i}=2.78 \times 10^{-13} \frac{S \rho_{2}}{Y m_{2}} & {\left[\text { ions } / \mathrm{m}^{2}-\mathrm{s}\right]}
\end{array}
$$

In Equation 11, $\mathrm{S}$ is the erosion rate $(\mu \mathrm{m} / \mathrm{khr}), \rho_{2}$ is the density of the keeper material $\left(\mathrm{kg} / \mathrm{m}^{3}\right), \mathrm{m}_{2}$ is the mass of the material (kg/atom), and the constant is used to correct $\mu \mathrm{m} / \mathrm{khr}$ to $\mathrm{m} / \mathrm{s}$. Finally, the flux required to produce a given erosion rate is equated with the directed flux of ions to the keeper surface, where the velocity of the ions is calculated from the ion energy in Equation 10. Equation 12 illustrates the erosion rate as a function of ion number density and energy for xenon bombardment.

$$
S=\frac{1}{2.78 \times 10^{-13}} \sqrt{\frac{2 e E}{m_{1}}} \frac{m_{2}}{\rho_{2}} Y n_{i} \quad[\mu \mathrm{m} / \mathrm{khr}]
$$

In Equation 12, $\mathrm{S}$ is erosion rate $(\mu \mathrm{m} / \mathrm{khr}), \mathrm{E}$ is ion energy $(\mathrm{eV})$, e is the elementary charge $\left(1.6 \times 10^{-19} \mathrm{C}\right), \mathrm{m}_{1}$ is the ion mass (kg/atom), $\mathrm{m}_{2}$ is keeper material mass ( $\mathrm{kg} /$ atom), $\rho_{2}$ is keeper material density $\left(\mathrm{kg} / \mathrm{m}^{3}\right), \mathrm{Y}$ is sputter yield (atoms/ion), $\mathrm{n}_{\mathrm{i}}$ is ion number density $\left(\mathrm{m}^{-3}\right)$, and the constant corrects units. Input parameters for the model are summarized in Table 2 .

In order to calculate the anticipated erosion rate of the dormant cathodes, representative inputs for plasma potential and number density are required. Results from the DCs suggest that for the two extreme operational configurations, $0 \mathrm{~A}$ and $+10 \mathrm{~A}$ electromagnet configurations, plasma potential and most-probable-voltage values are on the order of 27-35 V with respect to cathode common and number density ranges from $5.0 \times 10^{10}-5.5 \times 10^{11} \mathrm{~cm}^{-3}$. 
The 0 A condition typically has plasma potential and number densities of $27 \mathrm{~V}$ and $5.5 \times 10^{11} \mathrm{~cm}^{-3}$, respectively, where as the +10 A condition has values of $35 \mathrm{~V}$ and $5.0 \times 10^{10} \mathrm{~cm}^{-3}$, respectively. These values are utilized in the model to calculate the erosion rates shown in Figure 14.

Calculations resulting in an erosion rate of 0 are due to ion bombarding energies below the sputtering threshold energy. Erosion calculation results show Mo has the highest erosion rate, as expected. These results suggest that if the dormant cathode keepers are constructed of Mo they may suffer pre-operation erosion. In fact, the maximum measured DCA erosion rate is $70 \mu \mathrm{m} / \mathrm{khr},{ }^{10,37}$ which is only 1.8 times larger than the calculated dormant cathode Mo keeper erosion rate for the nominal $0 \mathrm{~A}$ electromagnet configuration at $40 \mathrm{deg}$. ion bombardment. At an erosion rate of $40 \mu \mathrm{m} / \mathrm{khr}$, a dormant cathode Mo

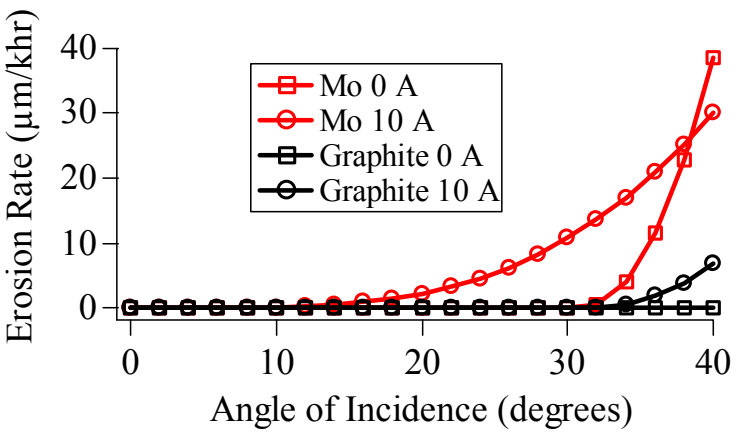

Figure 14: Dormant cathode erosion rate as a function of incidence angle for Mo and graphite keeper materials for the 0 A and 10 A configurations.

keeper erodes through its thickness after only 38,000 hours ( 4.4 years).

Although the model presented provides insight into dormant cathode erosion, multiple approximations have been made. The following list describes and justifies some of the shortcomings of the erosion model. 1) Limited lowenergy sputter data for graphite and molybdenum at normal and off-normal incidence are available, 2) Sputter threshold and yield data have large discrepancies (7-62 eV), $\left.{ }^{39} 3\right)$ Multiply-charged ion contribution is neglected, 4) Utilizing a directed flux overestimates the erosion rate because some ions are directed away from the DCs and toward the grid, 5) Normal incidence sputter data are used for off-normal erosion predictions.

These erosion prediction results suggest graphite is the best choice to reduce dormant cathode keeper erosion. However, other phenomenon may plague graphite keepers. Specifically residual amounts of oxygen impurity ions may strike the surface along with the xenon plasma ions. The sputter yield of high-energy oxygen ions on carbon is orders of magnitude larger than low-energy xenon ion bombardment. ${ }^{44}$ This effect must be better understood or eliminated, and further investigation into xenon-graphite sputtering behavior must be completed in order to validate graphite as an erosion-reducing, lifetime-increasing design solution.

\begin{tabular}{|c|c|c|c|c|c|c|}
\hline $\begin{array}{c}\text { Mission } \\
\text { Time (hrs): }\end{array}$ & Status & $\begin{array}{l}\text { CA \# } 1 \\
\text { Keeper } \\
\text { (\% remaining) } \\
\end{array}$ & Status & $\begin{array}{l}\text { A \# } 2 \\
\text { Keeper } \\
\text { (\% remaining) }\end{array}$ & Status & $\begin{array}{l}\text { A \# } 3 \\
\text { Keeper } \\
\text { (\% remaining) }\end{array}$ \\
\hline 0 & Active & 100 & Dormant & 100 & Dormant & 100 \\
\hline 15,000 & Active & 50 & Dormant & 90 & Dormant & 90 \\
\hline 30,000 & Eroded & 0 & Active & 80 & Dormant & 80 \\
\hline 54,400 & Eroded & 0 & Eroded & 0 & Active & 64 \\
\hline 73,900 & Eroded & 0 & Eroded & 0 & Eroded & 0 \\
\hline
\end{tabular}

Table 3: Predicted Mo keeper, triple-DCA MCDC ion thruster mission timeline.

Utilizing the erosion rates predicted by the erosion model, a MCDC ion thruster mission timeline can be determined. Dormant DCA Mo keeper erosion is assumed to be $10 \mu \mathrm{m} / \mathrm{khr}$ because recent results by Herman suggest ion incidence is primarily within 25-30 deg. with respect to keeper normal. ${ }^{41}$ Also, active DCA Mo keepers are assumed to erode at $50 \mu \mathrm{m} / \mathrm{khr}$, and a DCA is assumed terminated upon erosion through the keeper thickness (however, keeper erosion is not necessarily a DCA failure mechanism). Table 3 shows an example mission timeline for a Mo keeper, triple-DCA MCDC ion thruster. At 30,000 hours the first DCA keeper erodes and the second DCA is activated. However, at this point the second DCA keeper is already eroded through $20 \%$ of its thickness and is therefore only operational for 24,400 hours. When the third DCA is ignited only $64 \%$ of its keeper thickness remains so it's only operational for 19,500 hours. Although this analysis involves some simplifications, clearly a triple-DCA MCDC with Mo keepers does not provide a threefold increase in lifetime. Erosion of the dormant DCA keepers limits the lifetime increase provided by the addition of extra DCAs. However, this analysis suggests that utilizing three DCAs increases discharge chamber life by a factor of $\sim 2.5$ over that of a single-DCA. 


\section{Summary and Conclusions}

Dormant cathode plasma properties are analyzed using DCs designed to appear similar to the active DCA. Each DC is equipped with plasma probes such as Langmuir probes and a retarding potential analyzer. Five different DCs are utilized: a 5PLP-DC, 7PLP-DC, APLP-DC, ACLP-DC, and RPA-DC. Each DC is mounted at a dormant cathode location in a MCDC TA.

Results show no noticeable difference between operating the dormant cathodes electrically connected ("cathode" connected to cathode common and "keeper" connected to the anode through a $10 \mathrm{kOhm}$ resistor) or electrically isolated (both "cathode" and "keeper" floating) from the TA. As the electromagnet current increases, the backplate magnetic field increases, causing the near dormant cathode electron temperature and number density to decrease, where as the plasma potential increases. Furthermore, number density falls off two orders of magnitude within $5 \mathrm{~mm}$ internal to the dormant cathodes and data obtained internal to the DCs are more difficult to analyze due to a decreased signal-to-noise ratio.

For the nominal 0 A electromagnet configuration typical number density, electron temperature, and plasma potential values are on the order of $5.0 \times 10^{11} \mathrm{~cm}^{-3}, 5 \mathrm{eV}$, and $27.5 \mathrm{~V}$ with respect to cathode common, respectively. Plasma potentials are typically $2-4 \mathrm{~V}$ above the discharge voltage, which is nominally $24.5 \mathrm{~V}$. Results with the RPA suggest that ion most-probable-voltage ratio is as large as $29 \mathrm{~V}$ with respect to the cathode, which is consistent with an ion falling through the plasma potential.

Analysis of potential erosion rates of the dormant cathodes based on both Mo and graphite keepers are presented utilizing a sputtering yield model. Results indicate that Mo dormant cathode keepers may erode significantly faster than graphite keepers. In fact, the maximum measured DCA erosion rate is only 1.8 times larger than the maximum calculated dormant cathode Mo keeper rate. For the nominal 0 A electromagnet configuration, erosion rate calculations suggest a dormant cathode Mo keeper may erode between $0-40 \mu \mathrm{m} / \mathrm{khr}$ during off-normal ion bombardment, but a graphite keeper may not erode. However, before graphite can be declared an erosion solution, further study into the effects of oxygen ion bombardment on graphite keepers in ion thruster discharge chambers must be completed. Although a Mo dormant DCA keeper may suffer pre-operation erosion, a triple-DCA MCDC may still provide a factor of $\sim 2.5$ longer lifetime than a single-DCA.

\section{Future Work}

Further testing will involve investigating the plasma inside the MCDC using a Langmuir probe mounted to the PEPL High-speed Axial Reciprocating Probe (HARP) positioning system. Two-dimensional maps of the plasma properties will be obtained. Specifically, the near-DCA and near dormant cathode plasma will be characterized in order to understand better any potential erosion phenomena that may be present and to determine the optimum operational configuration of the dormant cathodes; electrically connected or isolated with propellant flow or no flow. Based on these results, specifically the plasma potential measurements, single-particle ion trajectories will be calculated to determine the initial positions and velocities of ions impacting the dormant cathodes and active DCA. These simulations will also be attempted using doubly-charged ions to determine if these ions contribute to dormant cathode erosion. Also, the TA plasma will be modeled utilizing the University of California at Berkeley plasma code XOOPIC. ${ }^{47}$ Data output by the code will be compared with experimentally measured plasma properties from this work, as well as from the HARP mapping described above. Results will provide insight into the operation of a MCDC and whether dormant cathode erosion is a life-limiting concern.

\section{Acknowledgments}

We would like to thank the entire research group at PEPL who have been instrumental in this investigation, Mr. Ryan Kurkul for assisting with the design and assembly of the 5PLP-DCs and 7PLP-DCs, Mr. Yassar Azziz for the miniature RPA drawings, and Mr. Terry Larrow for fabricating the hardware used in this study. We would also like to thank Mr. Michael Patterson of NASA GRC for the financial support of this research through research grant NNC04GA67G and for use of government furnished equipment. We would like to acknowledge Dr. John Foster (grant monitor) who has been the principal contact at NASA GRC. Mr. Joshua Rovey is additionally supported through a Michigan Space Grant Consortium graduate fellowship. This support is gratefully acknowledged.

\section{References}

${ }^{1}$ Dunning, J. W., Hamley, J., Jankovsky, R., Oleson, S., "An Overview of Electric Propulsion Activies at NASA," AIAA2004-3328, 40th Joint Propulsion Conference, Fort Lauderdale, FL, July 11-14, 2004. 
${ }^{2}$ Elliott, F., Foster, J. E., Patterson, M. J., "An Overview of the High Power Electric Propulsion (HiPEP) Project," AIAA2004-3453, 40th Joint Propulsion Conference, Fort Lauderdale, FL, July 11-14, 2004.

${ }^{3}$ Foster, J. E., Haag, T. W., Kamhawi, H., Patterson, M. J., Malone, S., Elliott, F., Williams, G. J., Sovey, J. S., Carpenter, C., "The High Power Electric Propulsion Thruster," AIAA-2004-3812, 40th Joint Propulsion Conference, Fort Lauderdale, FL, July 11-14, 2004.

${ }^{4}$ Patterson, M. J., Roman, R. F., Foster, J. E., "Ion Engine Development for Interstellar Precursor Missions," AIAA-20003811, 36th Joint Propulsion Conference, Huntsville, AL, July 16-19, 2000.

${ }^{5}$ Oleson, S., "Electric Propulsion Technology Development for the Jupiter Icy Moon Orbiter Project," AIAA-2004-3449, 40th Joint Propulsion Conference, Fort Lauderdale, FL., July 11-14, 2004.

${ }^{6}$ Rawlin, V. K., Williams, G. J., Pinero, L., Roman, R. F., "Status of Ion Engine Development for High Power, High Specific Impulse Missions," IEPC-01-096, 27th International Electric Propulsion Conference, Pasadena, CA, October 15-19, 2001.

${ }^{7}$ Sengupta, A., Brophy, J. R., Anderson, J. R., Garner, C. E., de Groh, K., Karniotis, T., Banks, B., "An Overview of the Results from the 30,000 Hr Life Test of Deep Space 1 Flight Spare Ion Engine," AIAA-2004-3608, 40th Joint Propulsion Conference, Fort Lauderdale, FL, July 11-14, 2004.

${ }^{8}$ Sengupta, A., Brophy, J. R., Goodfellow, K., "Status of the Extended Life Test of the Deep Space 1 flight spare engine after 30,352 hours of operation," AIAA-2003-4558, 39th Joint Propulsion Conference, Huntsville, AL, July 20-23, 2003.

${ }^{9}$ Kamhawi, H., Soulas, G. C., Patterson, M. J., Frandina, M. M., "NEXT Ion Engine 2000 Hr Wear Test Plume and Erosion Results," AIAA-2004-3792, 40th Joint Propulsion Conference, Fort Lauderdale, FL, July 11-14, 2004.

${ }^{10}$ Domonkos, M. T., Foster, C., Soulas, G. C., "Wear Testing and Analysis of Ion Engine Discharge Cathode Keeper," Journal of Propulsion and Power, Vol. 21, No. 1, pp. 102-110, Jan.-Feb. 2005.

${ }^{11}$ Poeschel, R. L., "Development of Advanced inert-gas ion thrusters," NAS3-22474, Hughes Research Laboratories, Malibu, June 1983.

${ }^{12}$ King, L. B., "Transport-Property and Mass Spectral Measurements in the Plasma Exhaust Plume of a Hall effect Space Propulsion System," Doctoral Thesis, Dept. of Aerospace Engineering, University of Michigan, Ann Arbor, 1998.

${ }^{13}$ Garner, C. E., Brophy, J. R., Polk, J. E., Pless, L. C., "Cyclic Endurance Test of a SPT-100 Stationary Plasma thruster," AIAA-94-2856, 30th Joint Propulsion Conference, Indianapolis, IN, June 27-29, 1994.

${ }^{14}$ Garner, C. E., Brophy, J. R., Polk, J. E., Pless, L. C., "A 5,730 Hr Cyclic Endurance Test of the SPT-100," AIAA-95-2667, 31st Joint Propulsion Conference, San Diego, CA, July 10-12, 1995.

${ }^{15}$ Day, M., Kim, V., Kozlov, V. I., Popov, G. A., Skrylnikov, A. I., "Investigation of the nonoperating cathode erosion reasons," AIAA-96-2710, 32nd Joint Propulsion Conference, Lake Buena Vista, FL, July 1-3, 1996.

${ }^{16}$ Dushman, S., Scientific Foundations of Vacuum Technique, Vol. 4, Wiley, New York, 1958.

${ }^{17}$ Walker, M. L. R., Gallimore, A. D., "Neutral density map of Hall thruster plume expansion in a vacuum chamber," Review of Scientific Instruments, Vol. 76, May 2005.

${ }^{18}$ Rovey, J. L., Gallimore, A. D., "Design and Operation of a Multiple-Cathode, High-Power, Rectangular Discharge Chamber," AIAA-2005-4407, 41st Joint Propulsion Conference, Tucson, AZ, July 10-13, 2005.

${ }^{19}$ Brophy, J. R., "Simulated Ion Thruster Operation Without Beam Extraction," AIAA-90-2655, 21st International Electric Propulsion Conference, Orlando, FL, July 18-20, 1990.

${ }^{20}$ Hutchinson, I. H., Principles of Plasma Diagnostics, Second Ed., Cambridge Universitiy Press, Cambridge, 2002.

${ }^{21}$ Hofer, R. R., "Development and Characterization of High-Efficiency, High-Specific Impulse Xenon Hall thrusters," Doctoral Thesis, Dept. of Aerospace Engineering, University of Michigan, Ann Arbor, MI, 2004.

${ }^{22}$ Azziz, Y., Martinez-Sanchez, M., Szabo, J., "Effects of Voltage and Plasma Oscillations on Plume Divergence of a High Specific-Impulse Hall thruster," AIAA-2005-4403, 41st Joint Propulsion Conference, Tucson, AZ, July 10-13, 2005.

${ }^{23}$ Herman, D. A., Gallimore, A. D., "Discharge Chamber Plasma Structure of a 30-cm NSTAR-type Ion Engine," AIAA2004-3794, 40th Joint Propulsion Conference, Fort Lauderdale, FL, July 11-14, 2004.

${ }^{24}$ Wilbur, P. J., Isaacson, J., "Plasma Property Contours in a $15 \mathrm{~cm}$ Hollow Cathode Kaufman thruster," Dept. of Mechanical Engineering, Colorado State University, Fort Collins, CO, February 1973.

${ }^{25}$ Goebel, D. M., Polk, J. E., Sengupta, A., "Discharge Chamber Performance of the NEXIS Ion Thruster," AIAA-2004-3813, 40th Joint Propulsion Conference, Fort Lauderdale, FL, July 11-14, 2004.

${ }^{26}$ Bohm, D., "Minimum Ionic Kinetic Energy for a Stable Sheath," The Characteristics of Electrical Discharges in Magnetic Fields, A. Guthrie and R. K. Wakerling, eds., McGraw-Hill Book Company, Inc., New York,1949.

${ }^{27}$ Laframboise, J. G., "Theory of Spherical and Cylindrical Langmuir probes in a Collisionless, Maxwellian Plasma at Rest," UTIAS Report No. 100, Institute for Aerospace Studies, University of Toronto, Toronto, Canada, June 1966.

${ }^{28}$ Steinbrüchel, C., Journal of the Electrochemical Society, Vol. 130, pp. 648,

${ }^{29}$ Chen, F. F., "Electric Probes," Plasma Diagnostic Techniques, R. H. Huddlestone and S. L. Leonard, eds., Academic Press, New York, 1965.

${ }^{30}$ Laframboise, J. G., Parker, L. W., "Probe Design for Orbit-Limited Current Collection," Physics of Fluids, Vol. 16, No. 5, pp. 629-636, May 1973.

${ }^{31}$ Beattie, J. R., "Numerical Procedure for Analyzing Langmuir Probe Data," AIAA Journal, Vol. 13, No. 7, pp. 950-952, July 1975.

${ }^{32}$ Reinsche, C. H., "Smoothing by spline functions," Numerische Mathematik, Vol. 10, pp. 177-183, 1967.

${ }^{33}$ Foster, J. E., Gallimore, A. D., "The effect of an auxiliary discharge on anode sheath potentials in a transverse discharge," Journal of Applied Physics, Vol. 81, No. 8, pp. 3422-3432, April 1997. 


\footnotetext{
${ }^{34}$ Patterson, M. J., "Performance Characteristics of Ring-Cusp Thrusters with Xenon Propellant," AIAA-86-1392, 22nd Joint Propulsion Conference, Huntsville, AL, June 16-18, 1986.

${ }^{35}$ Sovey, J. S., "Improved Ion Containment using a Ring-Cusp Ion thruster," Journal of Spacecraft and Rockets, Vol. 21, No. 5, pp. 488-495, Sept. - Oct. 1984.

${ }^{36}$ Patterson, M. J., Rawlin, V. K., Sovey, J. S., Kussmaul, M. J., Parkes, J., "2.3 kW Ion Thruster Wear Test," AIAA-95-2516, 31st Joint Propulsion Conference, San Diego, CA, July 10-12, 1995.

${ }^{37}$ Polk, J. E., Anderson, J. R., Brophy, J. R., Rawlin, V. K., Patterson, M. J., Sovey, J. S., Hamley, J., "An Overview of the Results from an 8200 Hour Wear Test of the NSTAR Ion thruster," AIAA-99-2446, 35th Joint Propulsion Conference, Los Angeles, California, June 20-24, 1999.

${ }^{38}$ Duchemin, O. B., Brophy, J. R., Garner, C. E., Ray, P. K., Shutthanandan, V., Mantenieks, M. A., "A Review of Low Energy Sputtering Theory and Experiments," IEPC-97-068, 25th International Electric Propulsion Conference, Cleveland, OH, August 24-28, 1997.

${ }^{39}$ Nakles, M. R., "Experimental and Modeling Studies of Low-Energy Ion Sputtering for Ion Thrusters," Masters Thesis, Dept. of Aerospace Engineering, Virginia Polytechnic Institute and State University, Blacksburg, VA, 2004.

${ }^{40}$ Yamamura, Y., "Threshold Energies of Light-Ion Sputtering and Heavy-Ion Sputtering as a function of Angle of Incidence," Nuclear Instruments and Methods in Physics Research B2, pp. 627-630, 1984.

${ }^{41}$ Herman, D. A., "The Use of Electrostatic Probes to Characterize the Discharge Plasma Structure and Identify Discharge Cathode Erosion Mechanisms in Ring-Cusp Ion Thrusters," Doctoral Thesis, Dept. of Aerospace Engineering, University of Michigan, Ann Arbor, MI., 2005.

${ }^{42}$ Williams, G. J., "The Use of Laser-Induced Fluorescence to Characterize Discharge Cathode Erosion in a $30 \mathrm{~cm}$ Ring-Cusp Ion thruster," Doctoral Thesis, Dept. of Aerospace Engineering, University of Michigan, Ann Arbor, MI., 2000.

${ }^{43}$ Wilhelm, H. E., "Quantum-statistical Analysis of Low-Energy Sputtering," Australian Journal of Physics, Vol. 38, No. 2, pp. 125-133, 1985.

${ }^{44}$ Doerner, R. P., Whyte, D. G., Goebel, D. M., "Sputtering yield measurements during low energy xenon plasma bombardment," Journal of Applied Physics, Vol. 93, No. 9, pp. 5816-5823, May 2003.

${ }^{45}$ Stuart, R. V., Wehner, G. K., "Sputtering Yields for Low Energy $\mathrm{He}^{+}-, \mathrm{Kr}^{+}-$, and $\mathrm{Xe}^{+}-$Ion Bombardment," Journal of Applied Physics, Vol. 33, No. 5, pp. 1842-1845, May 1962.

${ }^{46}$ Duchemin, O. B., "An Investigation of Ion Engine Erosion by Low Energy Sputtering," Doctoral Thesis, California Institute of Technology, Pasadena, CA, 2001.

${ }^{47}$ Verboncoeur, J. P., Langdon, A. B., Gladd, N. T., "An object-oriented electromagnetic PIC code," Computer Physics Communications, Vol. 87, pp. 199-211, May 1995.
}

\section{Appendix A: MCDC TA Operational Configurations}

\begin{tabular}{|cccccccc|}
\hline Configuration & DCA & $\begin{array}{c}\mathrm{I}_{\mathrm{d}} \\
(\mathrm{A})\end{array}$ & $\begin{array}{c}\mathrm{V}_{\mathrm{d}} \\
(\mathrm{V})\end{array}$ & $\begin{array}{c}\text { Mass flow, } \\
\text { cathode }(\mathrm{sccm})\end{array}$ & $\begin{array}{c}\text { Mass flow, } \\
\text { anode }(\mathrm{sccm})\end{array}$ & $\begin{array}{c}\mathrm{I}_{\text {emag }} \\
(\mathrm{A})\end{array}$ & $\begin{array}{c}\text { DC Electrical } \\
\text { Connectivity }\end{array}$ \\
\hline 0LC & Left & 30 & 24.5 & 6.12 & 30.9 & 0 & Connected \\
0MC & Center & 30 & 24.4 & 5.73 & 30.9 & 0 & Connected \\
0RC & Right & 30 & 25.1 & 6.12 & 30.9 & 0 & Connected \\
\hline 5LC & Left & 30 & 25.8 & 6.12 & 30.9 & 5 & Connected \\
5MC & Center & 30 & 25.5 & 5.73 & 30.9 & 5 & Connected \\
5RC & Right & 30 & 26.2 & 6.12 & 30.9 & 5 & Connected \\
\hline 10LC & Left & 30 & 28.2 & 6.12 & 30.9 & 10 & Connected \\
10MC & Center & 30 & 27.3 & 5.73 & 30.9 & 10 & Connected \\
10RC & Right & 30 & 28.6 & 6.12 & 30.9 & 10 & Connected \\
\hline 0LI & Left & 30 & 24.5 & 6.12 & 30.9 & 0 & Isolated \\
0MI & Center & 30 & 24.4 & 5.73 & 30.9 & 0 & Isolated \\
0RI & Right & 30 & 25.1 & 6.12 & 30.9 & 0 & Isolated \\
\hline 5LI & Left & 30 & 25.8 & 6.12 & 30.9 & 5 & Isolated \\
5MI & Center & 30 & 25.5 & 5.73 & 30.9 & 5 & Isolated \\
5RI & Right & 30 & 26.2 & 6.12 & 30.9 & 5 & Isolated \\
\hline 10LI & Left & 30 & 28.2 & 6.12 & 30.9 & 10 & Isolated \\
10MI & Center & 30 & 27.3 & 5.73 & 30.9 & 10 & Isolated \\
10RI & Right & 30 & 28.6 & 6.12 & 30.9 & 10 & Isolated \\
\hline
\end{tabular}

